\title{
Dynamic Price Competition with Fixed Capacities
}

\author{
Victor Martínez-de-Albéniz* \\ Kalyan Talluri ${ }^{\dagger}$
}

February 26, 2010

\begin{abstract}
Many revenue management (RM) industries are characterized by (a) fixed capacities in the short term (e.g., hotel rooms, seats on an airline flight), (b) homogeneous products (e.g., two airline flights between the same cities at similar times), and (c) customer purchasing decisions largely influenced by price. Competition in these industries is also very high even with just two or three direct competitors in a market. However, RM competition is not well understood and practically all known implementations of RM software and most published models of RM do not explicitly model competition. For this reason, there has been considerable recent interest and research activity to understand RM competition. In this paper we study price competition for an oligopoly in a dynamic setting, where each of the sellers has a fixed number of units available for sale over a fixed number of periods. Demand is stochastic, and depending on how it evolves, sellers may change their prices at any time. This reflects the fact that firms constantly, and almost costlessly, change their prices (alternately, allocations at a price in quantity-based $\mathrm{RM}$ ), reacting either to updates in their estimates of market demand, competitor prices, or inventory levels. We first prove existence of a unique subgame-perfect equilibrium for a duopoly. In equilibrium, in each state sellers engage in Bertrand competition, so that the seller with the lowest reservation value ends up selling a unit at a price that is equal to the equilibrium reservation value of the competitor. This structure hence extends the marginal-value concept of bid-price control, used in many RM implementations, to a competitive model. In addition, we show that the seller with the lowest capacity sells all its units first. Furthermore, we extend the results transparently to $n$ firms and perform a number of numerical comparative statics exploiting the uniqueness of the subgame-perfect equilibrium.
\end{abstract}

Keywords: revenue management, bid-prices, subgame-perfect equilibrium.

\section{Introduction}

Revenue management (RM) is the control of the sale of a limited quantity of a resource (hotel rooms for a night, airline seats, advertising slots etc.) to a potential set of customers (the market). The resource is perishable, and for the sake of simplicity, we assume that it perishes at a fixed point

\footnotetext{
*Victor Martínez-de-Albéniz, IESE Business School, Av. Pearson 2108034 Barcelona, Spain, email: valbeniz@iese.edu

${ }^{\dagger}$ Kalyan Talluri, ICREA and UPF, Universitat Pompeu Fabra, Ramon Trias Fargas 25-27, 08005 Barcelona, Spain, email: kalyan.talluri@upf.edu
} 
of time in the future. Customers are independent of each other, arrive randomly during the sale period, and demand one unit of resource each. Sale is online, so firms have to set their prices at the time of each customer's arrival. The reader should consult the books by Talluri and van Ryzin [34] or Phillips [32] for a background on the theory and a survey of applications of revenue management.

While a significant body of research in RM has been developed over the last decade, much of it is concerned with a better modeling of customer behavior (discrete-choice modeling of demand, strategic customers, etc.) or in jointly optimizing multiple resources (network revenue management). In contrast, the literature that studies the role of competition in revenue management has been relatively sparse. Part of the reason could be that when one adds capacity constraints, even relatively simple models such as the Bertrand-Edgeworth model lack pure-strategy equilibria making them difficult to extend to more complicated RM situations (Netessine and Shumsky[29]).

In contrast to the negative results and difficulties associated with the Bertrand-Edgeworth model of competition, Dudey [13], somewhat surprisingly, shows that the dynamic version of BertrandEdgeworth duopoly competition with a known and fixed market size has a unique subgame-perfect equilibrium. The work of Dudey [13] has some bearing on RM as (i) in many RM situations, such as an airline market served by low-cost carriers, price is the main consideration for customers and there is very little brand or product differentiation, (ii) a dynamic model of competition reflects operational RM price-setting behavior better, and (iii) it holds the promise that by modeling the dynamics of competition one can obtain better predictions of equilibrium behavior and thereby get some managerial insight into the nature of RM competition. It therefore appears to be the right starting point to study competition in RM, with the objective of gradually relaxing some of the assumptions of his model and make it more relevant to an operational problem such as RM.

In this paper we study a dynamic model of price competition between sellers who offer an identical resource with limited capacities and a stochastic market demand. Our model, while stylized and simplified, is intended to reflect the competitive considerations of a revenue manager at a hotel or airline who sets prices daily for products that compete directly with another firm. We generalize and simplify Dudey's [13] results, showing that under a more general model, the equilibrium behavior of a duopoly (that we later generalize to $n$ firms) can be characterized by a simple "competitive bidprice" type of rule: each firm calculates a competitive (equilibrium) reservation value, and in each period, the firm with the lower reservation value makes the sale at a price equal to the other firm's reservation value. This is the unique subgame-perfect equilibrium. This interpretation is appealing for two reasons. First, showing that there is a unique equilibrium during the price-competition phase allows us to study numerically a number of difficult strategic questions, such as capacity choice, overall market profits and market entry. Second, many RM systems use the concept of bidprice control: they sell the resource at all prices higher than a threshold value that is a function of remaining capacity and time. In that respect, our results show how competition influences the bid-price.

Our results also highlight the critical role of capacity asymmetries in determining the degree of competition and the profits obtained. When capacities are unequal, the lower-capacity firm always has a lower reservation value, sells first, and continues to sell until it exhausts capacity. The highercapacity firm has no choice but to wait until the other firm sells out and profits by charging monopoly price for the residual demand. Nevertheless, its competitive presence forces the lower-capacity firm to price much lower than the monopoly price - even when both firms know that the customers are price-insensitive. The degree of profits will depend on the overall market size.

The rest of the paper is organized as follows. In $\S 2$ we review the relevant literature from economics and operations management. We then present our model in $\S 3$, and in $\S 4$ the main analytical 
results, first for a duopoly and then to $n$ firms. In $\S 5$ we use the equilibrium characterization to study numerically a number of interesting questions as to how profits change as a function of capacity and market size. Finally in $\S 6$ we conclude with a summary of contribution and directions for future research.

\section{Literature Review}

We divide the review into static and dynamic models of competition.

\subsection{Static models}

The two classic models of oligopoly are the Cournot model (competition in quantities [8]) and the Bertrand model (competition in prices [4]). In the Cournot model, $n$ firms first choose their production quantity simultaneously, and the market then determines the price that clears total output. In the Bertrand model of price competition, firms produce an identical commodity and customers buy only from firms offering the lowest price. Firms compete on price, and it is assumed that each firm produces a quantity sufficient to satisfy all the demand it faces at its offered price: this results in a unique equilibrium in which firms price at their marginal cost and make zero profits.

The Bertrand model can be thought of representing a sort of extreme competition, where the product is essentially a "commodity" and price is the only factor influencing customer purchases. As one can expect, the intensity of competition is less for differentiated products. There is a considerable amount of literature on competition amongst differentiated products. Many of these models are based on the discrete-choice model of customer purchases (specifically logit, with a single customer segment), with the product attributes marking differentiation and probabilities of purchase. The main advantage of such models is that each firm's profit is pseudo-concave in its own price, leading to a price-equilibrium (Anderson, Palma and Thisse [2]).

In this paper we are mainly concerned with Bertrand competition, but with capacity constraints. This is commonly called the Bertrand-Edgeworth model (Edgeworth [14]). In this model, consumers buy at the firm with the lowest price and if two firms have identical prices, they choose one at random. They arrive in a random order, independent of their valuations. A pure-strategy equilibrium need not exist in such a case. However, mixed-strategy equilibria exist ([1], [26], [9]); see Levitan and Shubik [26] for a proof of this result and also for further details on the Bertrand, Cournot and the Bertrand-Edgeworth models.

The equilibrium for the (static) Bertrand-Edgeworth competition game for $n$-firms with arbitrary capacities is not well understood. Hirata [20] and De Francesco and Salvadori [11] are two recent articles which characterize the mixed-strategy equilibria for tripolies. Hirata [20] finds that the smallest capacity firm can earn the most profits per unit of capacity in equilibrium, a finding that can happen under some circumstances in our model.

The Bertrand-Edgeworth model seems the ideal starting point for exploring revenue management competition. In most revenue management situations capacity is fixed in the short-term (such as the number of hotel rooms, or airplane capacity), and the competition is usually based on price. The lack of a pure-strategy equilibrium however is somewhat discouraging. If even the simplest case gives no clear prediction as to what will happen in equilibrium, introducing more complicated phenomenon such as multiple customer segments and capacity choice would not make the analysis 
any easier.

With a specific RM situation in mind, Netessine and Shumsky [29] study the Bertrand-Edgeworth model with two customer types in a duopoly. Both firms have a fixed capacity but sell in two classes, denoted $H$ (high) and $L$ (low). Each firm offers identical prices $p_{L}<p_{H}$ (fixed exogenously). Customers substitute among airlines within the same class, and the strategic decisions are how much of the capacity to allocate to class $L$. They show that there is no equilibrium in general and give sufficient conditions on the demand distributions (total positivity) for guaranteeing one. In an equilibrium they show that more seats are protected for higher-fare customers than in a monopoly. In a similar vein, Zhao [35] and $\mathrm{Li}$ et al. [27] consider static RM competition with two customer classes. Zhao [35] considers a two-stage model where prices for two classes are set first and then the firms set allocations for the two classes. Under a spill-over model, different from that of [29], he shows that both price and protection levels are lower when the firms compete on prices as well as allocations. Li et al. [27] consider a model similar to [29] but with cost asymmetries and a different spill model. They establish sufficient conditions for a unique pure-strategy equilibrium, and obtain a result similar to that of Zhao [35] on allocations for the higher-fare customers.

For reasons of brevity, we leave out the vast literature on Cournot competition, except to mention the work that considers a two-stage game where firms first set capacities (Cournot) and then in the second-stage set prices (Bertrand). The interest in this model increased considerably after Kreps and Scheinkman [23] showed that the two-stage game has a unique equilibrium that coincides with the Cournot outcome, thus validating the Cournot model. However, note that both stages of the game are static, and in such models one has to define how demand flows between the two firms. Kreps and Scheinkman [23] use a form called efficient rationing (highest valuation customers served first), whereas Davidson and Deneckere [10] show that the result does not hold if one considers an alternate proportional rationing scheme (akin to random assignment). We mention these results because in the numerical results of $\S 5.4$ we investigate a firm's capacity choice in a two-stage game where in the first stage firms choose capacity, and then compete setting dynamic prices.

\subsection{Dynamic models of competition}

Chamberlin [6] was one of the first economists to point out that repeated interaction between oligopolists can facilitate collusion. With repeated interactions firms can threaten retaliation (price wars) and thus ensure that competitors do not deviate from collusive prices.

One of the earliest papers studying dynamic price competition with capacity constraints is Dudey [13] who showed the existence of a unique subgame-perfect equilibrium, in contrast to the classical non-existence result of Edgeworth. The value of showing uniqueness of the equilibrium cannot be underestimated. To quote Osborne and Pitchuk [30], “... (non-uniqueness) causes problems in economic applications, since without a uniqueness result we do not know if the characteristics of a particular equilibrium are shared by others, and we cannot legitimately perform comparative static exercises."

In general it is difficult to prove the existence of subgame-perfect equilibria in a (finite) multiperiod stochastic game, and there are very few general results to aid such proof, so we believe Dudey [13] should be the right base for investigating dynamic RM competition. Firms charge prices other than the valuations - zero or even negative prices - for purely competitive reasons rather than for price discrimination, highlighting the havoc pure competition can play with prices.

Biglaiser and Vettas [5] study a dynamic price game where the firms have fixed, limited capacities 
and the customers are strategic. They find that there is no pure-strategy subgame-perfect equilibrium, and seller's market shares tend to by maximally asymmetric with high probability (somewhat reflected by our results also). In a model very relevant to RM, and like ours based to a good extent on Dudey [13], Anderson and Schneider [3] study dynamic price competition. Their main emphasis is the role of search costs on the equilibrium output and surprisingly they show that when search costs are present duopoly prices are higher than charged by a monopolist.

In the operations research/management literature, notable works closest to our research are Perakis and Sood [31] and Gallego and $\mathrm{Hu}$ [17]. Perakis and Sood [31] study an open-loop equilibrium (prices are fixed for the entire horizon, and the prices need not be subgame-perfect) using variational inequality tools and perform comparative statics on equilibrium prices as a function of demandcapacity ratios. Gallego and $\mathrm{Hu}$ [17] study a stochastic differential game of duopoly competition and give sufficient conditions for the existence of open-loop and closed-loop Nash equilibria. Their aim is to develop efficient pricing heuristics predicted by these equilibrium paths.

Finally, there is a fairly large body of work on dynamic versions of differentiated-product price competition. Some sample publications that extend the discrete choice one-period models considered in ([2])are: in economics, [28], marketing, [7], and operations [18], [25],[33]. Talluri [33] points out the role of observability in a dynamic capacity RM allocation control game. While the concept of Nash equilibrium is independent of observability of the strategy parameters, it is still unsatisfactory to model best-response functions that assume the players can observe the competitor's capacity, when in reality one cannot. The role of unobservability is an interesting research problem for operational applications, that we believe deserves more attention.

\section{The Duopoly Model}

We consider two firms $A$ and $B$ that have a number of units to be sold before a deadline. We denote by $x_{0 A}$ and $x_{0 B}$ respectively the capacities available initially (at time 0 ). One can think of these capacities as the number of seats on a flight that can be sold before departure. We initially assume that the variable (marginal) cost of selling a unit is zero, but this is relaxed in $\S 4.4$. Although we focus on the case of two firms, the model and the results are extended to $n>2$ firms in $\S 4.5$.

A number of customers would like to buy the units sold by the two firms. These customers value the product at a common fixed value $v>0$ (the relaxation of this assumption is discussed in §4.4). The customers arrive sequentially to the market, and demand exactly one unit. When a customer arrives, each seller quotes a price, and the customer purchases the unit from the lowest-price firm, provided that the price is less than her valuation $v$. If the two firms offer the same price below $v$ then the customer chooses one randomly with probability 0.5 . For example, in the airline industry, it is common that when a customer receives two quotes for two identical flights of two airlines from an internet travel agent, she is indifferent about the airline brand. Finally, a customer who cannot purchase because prices are higher than her valuation leaves the system - that is, she does not try again. In that sense, we are assuming that customers are not strategic - their arrival time is determined by nature.

We are interested in the pricing policies that the sellers will set, under competition, for the stochastic pool of customers. 


\subsection{Modeling the Demand Process}

As in most practical cases, the total number of customers interested in the product is unknown to the sellers. In order to model the information available to the sellers, we consider a finite number of periods in which sales can occur, $t=0, \ldots, T$. In each period, both sellers observe whether one or zero customers arrive. With this information, and possibly other external information (such as macroeconomic changes that affect the arrival distribution), the sellers update their information for the next period.

Formally, we denote $I_{t}$ the information available to both sellers at the beginning of period $t$. For simplicity, we assume that $I_{t}$ can take a finite number of values, in the set $\mathbf{S}_{t}$. We denote as $\tilde{S}_{I_{t}}$ the random variable equal to one if a customer arrives at $t$ and zero otherwise. Let $\tilde{R}_{I_{t}}$ be the remaining number of customers from period $t$ until $T$. Both firms have the same available information, and we assume they share the same forecast on the distribution of $\tilde{R}_{I_{t}}$. We denote $F_{I_{t}}$ the cumulative distribution function (c.d.f.) of $\tilde{R}_{I_{t}}$, i.e., $F_{I_{t}}(x)=\operatorname{Pr}\left[\tilde{R}_{I_{t}} \leq x\right]$, and $\bar{F}_{I_{t}} \equiv 1-F_{I_{t}}$. We make no distributional assumptions on $\tilde{R}_{I_{t}}$, except that for all $t, I_{t}$, it is bounded above by $T-t+1$, the number of periods to go, i.e., $F_{I_{t}}(T-t+1)=1$ (which is reasonable since $T$ can be set as high as needed). Note that one can specify any distribution for $\tilde{R}_{I_{t}}$, which allows the firms to fit the variance in the observed data.

The evolution of the information might be random. Specifically, we can define a transition probability from any state $I_{t} \in \mathbf{S}_{t}$ to $I_{t+1} \in \mathbf{S}_{t+1}$.This model is quite flexible and allows modeling correlated demand processes. In particular, it captures some common models from the literature, as shown through the two examples below. As we mentioned earlier, both firms have the same information and they know that the competitor also has access to the same information.

Poisson demand process. One simple case captured by the model is the case of arrivals that are independent over time. Denote as $\lambda_{t} \in[0,1]$ as the probability that a customer arrives at $t$, independent of past arrivals. In this case, the only information that the sellers need to know to forecast future arrivals, $I_{t}$, only takes one value: $\left(\lambda_{t}, \ldots, \lambda_{T}\right)$. The transitions in this case are deterministic, i.e., we move from $\left(\lambda_{t}, \ldots, \lambda_{T}\right)$ to $\left(\lambda_{t+1}, \ldots, \lambda_{T}\right)$ with probability one. One can see that as one chooses a finer discretization of the selling period, i.e., $T \rightarrow \infty$, this demand process can model a non-homogeneous Poisson process, as in Gallego and van Ryzin [19].

Uncertain market size. One other application of the general demand model is the case where all the relevant information is contained in the number of past arrivals. In other words, all the uncertainty is contained in $\tilde{M} \leq T+1$ the random variable that determines the total, potential, market size. When $\tilde{M}$ is deterministic, the model coincides with the one studied in Dudey [13] and Anderson and Schneider [3]. If $\tilde{M}$ is non-deterministic, as customers arrive, the distribution of $\tilde{M}$ can be updated as new customers arrive. Specifically, the information $I_{t}$ is the knowledge of whether more customers will arrive or not (given by how many customers have arrived until now). In particular, $I_{t}=(t, Y)$ if more customers may arrive, and $I_{t}=(t, N)$ otherwise. Initially, $I_{0}=(0, Y)$, and the c.d.f. of $\tilde{M}=\tilde{R}_{I_{0}}$ is the prior distribution of the market size, denoted $G_{\tilde{M}}$. In every period $t$, a customer arrives if and only if $\tilde{M}>t$. Hence, at $t$, if $I_{t}=(t, Y), t$ customers have arrived. Hence, the distribution of $\tilde{R}_{I_{t}}=\tilde{M}-t$, depends on the conditional distribution of $\tilde{M}$ given that $t$ customers have arrived. The conditional distribution of $\tilde{R}_{I_{t}}$ is given by $G_{t}$, defined recursively by

$$
G_{t}(x)=\operatorname{Pr}\left[\tilde{R}_{I_{t}} \leq x \mid \tilde{M} \geq t\right]=\frac{G_{\tilde{M}}(t+x)-G_{\tilde{M}}(t-1)}{1-G_{\tilde{M}}(t-1)}, \text { for all } x \geq 0
$$


On the other hand, if $I_{t}=(t, N)$, then the sellers know that no more customers will arrive, in which case $\tilde{R}_{I_{t}}=0$ with probability one. In this model, $\mathbf{S}_{t}=\{(t, Y),(t, N)\}$ and the transition probabilities are: from $(t, N)$ to $(t+1, N), 1$; from $(t, N)$ to $(t+1, Y), 0$; from $(t, Y)$ to $(t+1, N)$, $\frac{G_{\tilde{M}}(t)-G_{\tilde{M}}(t-1)}{1-G_{\tilde{M}}(t-1)}$; and from $(t, Y)$ to $(t+1, Y), \frac{1-G_{\tilde{M}}(t)}{1-G_{\tilde{M}}(t-1)}$.

\subsection{Revenue Management with Bid-Prices}

In each period, each seller prices its capacity dynamically. In order to set this price, it can use the information on:

- future demand, available at $t, I_{t}$;

- its own capacity, denoted $x_{t, A}\left(x_{t, B}\right)$;

- the competitor's capacity $x_{t, B}\left(x_{t, A}\right)$.

Thus, we assume that each seller can observe the capacity of the competitor. Similarly, we assume that both firms see all customer arrivals and their purchases. While these assumptions on observability are standard in game theory and Economics, in $§ 5.2$ we point out how this information can in fact be deduced from the equilibrium price path.

Given current information $I_{t}$ and capacities of the firms are $x_{t, A}, x_{t, B}$, firms simultaneously set prices $p_{t, A}, p_{t, B}$. If $x_{t, A}=0\left(x_{t, B}=0\right)$, we assume that $p_{t, A}=v+1\left(p_{t, B}=v+1\right)$, the quoted price of firm $A$ (respectively $B$ ) is high enough to reject customers if there is no capacity left.

If a customer arrives in a period, she purchases a unit at the lowest-price firm, provided that the quoted price is lower than her reservation value $v$. Hence, given the prices, we can define the probability that customer chooses firm $A$ as $P_{A}\left(p_{t, A}, p_{t, B}\right)$ given by

$$
P_{A}\left(p_{t, A}, p_{t, B}\right)= \begin{cases}1 & \text { if } p_{t, A}<p_{t, B} \text { and } p_{t, A} \leq v \\ 0.5 & \text { if } p_{t, A}=p_{t, B} \\ 0 & \text { otherwise }\end{cases}
$$

$P_{B}\left(p_{t, A}, p_{t, B}\right)$ is defined identically.

Given current capacities $x_{t, A}, x_{t, B}$ and current information $I_{t}$, a firm's objective is to maximize its revenue-to-go. In other words, a firm will set the price that maximizes the revenue from selling its capacity over the remaining sale period. Since the firm is facing competition, its pricing strategy will depend on the competitor's price strategy. We thus require game-theoretical tools to solve the problem. Specifically, we are interested in finding equilibrium price strategies, i.e., a set of price policies $\left\{\mathbf{p}_{A}, \mathbf{p}_{B}\right\}:=\left\{p_{t, A}\left(x_{t, A}, x_{t, B}, I_{t}\right), p_{t, B}\left(x_{t, A}, x_{t, B}, I_{t}\right)\right\}$ from which no firm has a unilateral incentive to deviate. Since the decisions can be modified in each period, these strategies will have to be subgame-perfect. A subgame-perfect equilibrium is one in which the equilibrium is simultaneously a Nash equilibrium for every subgame (the game from any subsequent stage assuming all the information on actions from the previous stages) of the initial game. See Fudenberg and Tirole [15] for a formal definition in terms of the extensive-form of a game.

We illustrate the concept using an example in the pricing context. Consider a $T$ period, two-player (denoted $A, B$ ), Bertrand pricing game where prices are the strategic variables. Then 
$\left[\left(p_{1, A}, p_{1, B}\right), \ldots,\left(p_{T, A}, p_{T, B}\right)\right]$ is subgame-perfect equilibrium if (i) it is a Nash-equilibrium and (ii) for all $t, 1<t \leq T$, the decisions $\left[\left(p_{t, A}, p_{t, B}\right), \ldots,\left(p_{T, A}, p_{T, B}\right)\right]$ form a Nash equilibrium for the subgame starting from period $t$ to period $T$.

Subgame-perfect equilibria are sometimes also referred to as closed-loop equilibria or equilibria with feedback.

\subsection{Static and Open-loop Strategies}

While the non-existence of equilibrium for the Bertrand-Edgeworth model (the Edgeworth cycle) is well known, we recall it here for completeness and to contrast with the dynamic game. Consider a duopoly with both firms having two units of capacity each and three customers each with valuation of 1 over three periods, known to both firms. So assume one of the firms, say A, sets price $p_{A} \leq p_{B}$ in equilibrium. For firm B not to undercut firm A, it must be true that $2 p_{A} \leq p_{B}$ (in which case, its best price is $p_{B}=1$ ). Meanwhile, firm $\mathrm{A}$ is better off pricing just below $p_{B}$. Hence, there can be no equilibrium.

Alternatively, one can look for an open-loop equilibrium using dynamic prices. Open-loop equilibrium (or non-feedback equilibrium) is an equilibrium concept sometimes applied in dynamic pricing models of competition (for instance, see [17] or [31]). Competing firms solve a single optimization problem at the beginning to set prices over the entire pricing horizon, rather than solve a dynamic program that sets policies based on current time and inventories. As mathematical programs are somewhat easier to analyze than dynamic programs, studying open-loop equilibria tends to be more tractable. Of course, it needs a somewhat strong assumption that firms commit to the prices that they set in the beginning.

In the Bertrand-Edgeworth model, even with our simple model of known valuations, openloop equilibria may fail to exist. In the above example, the firms set prices $\left\{p_{1, A}, p_{2, A}, p_{3, A}\right\}$ and $\left\{p_{1, B}, p_{2, B}, p_{3, B}\right\}$, for each of the three periods. Using the indicator function $\mathbb{1}_{[E]}$ to denote 1 if event $E$ occurs and 0 otherwise, and the operator $\vee$ to represent "or", and $\wedge$ to represent "and", expected revenue for firm 1 is then

$$
\begin{gathered}
p_{1, A}\left(\mathbb{1}_{\left[p_{1, A}<p_{1, B}\right]}+0.5 \mathbb{1}_{\left[p_{1, A}=p_{1, B}\right]}\right)+p_{2, A}\left(\mathbb{1}_{\left[p_{2, A}<p_{2, B}\right]}+0.5 \mathbb{1}_{\left[p_{2, A}=p_{2, B}\right]}\right) \\
+p_{3, A}\left(\mathbb{1}_{\left[p_{3, A}<p_{3, B}\right]}+0.5 \mathbb{1}_{\left[p_{3, A}=p_{3, B}\right]}\right) \mathbb{1}_{\left[x_{3, A}>0\right]}
\end{gathered}
$$

where $\mathbb{1}_{\left[x_{3, A}>0\right]}=\mathbb{1}_{\left[\left(p_{1, A}>p_{1, B}\right) \vee\left(p_{2, A}>p_{2, B}\right)\right]}+0.75 \mathbb{1}_{\left[\left(p_{1, A}=p_{1, B}\right) \wedge\left(p_{2, A}=p_{2, B}\right)\right]}$.

If $p_{3, A}>p_{3, B}$ and firm $\mathrm{A}$ is not sold out, it always has an incentive to undercut $\mathrm{B}$ unless $p_{3, B}=0$. Otherwise, A has a zero probability of having capacity left in period $3\left(p_{1, A}<p_{1, B}\right.$ and $\left.p_{2, A}<p_{2, B}\right)$. But if either $p_{1, A}$ or $p_{2, A}$ are greater than 0 , firm $\mathrm{B}$ is better off undercutting firm $\mathrm{A}$ in that period. So, in any equilibrium either $p_{1, A}=p_{2, A}=0$ or $p_{3, B}=0$. But if $p_{1, A}=p_{2, A}=0$ firm $\mathrm{B}$ is better off pricing $p_{3, B}=1$ in which case firm $\mathrm{A}$ would not price $p_{1, A}=p_{2, A}=0$ as it is better off to reach period 3 with positive capacity.

Next, $p_{3, A}=p_{3, B}$ can be an equilibrium only if there is a positive probability of arriving with positive capacity at stage 3 for both firms, in which case $p_{3, A}=p_{3, B}=0$, as otherwise each has an incentive to undercut the other. Furthermore, if in either period 1 or 2 , say period 1 , $0<p_{1, A}<p_{1, B}$, firm $\mathrm{B}$ then is better off undercutting $\mathrm{A}$ in that period, so we should have $p_{1, A}=p_{1, B}=p_{2, A}=p_{2, B}=0$, but then firm $\mathrm{B}$ (or $\mathrm{A}$ ) is better off pricing at 1 in all three periods. Hence, no open-loop equilibrium exists.

Thus, in this example, both the static and open-loop models are not capable of generating enough 
threats and responses between the firms to enforce an equilibrium.

\subsection{Subgame-perfect Strategies}

In contrast with static and open-loop strategies, closed-loop (i.e., subgame-perfect) policies, are the most natural type of policies in a dynamic price-setting game when firms can freely adjust prices to the current state of the system (current capacities, current information).

In equilibrium, each firm's price policy is the best-response to the competitor's policy. Consider the decision of firm $A$, at time $t$. To simplify the exposition, we remove the index $t$ from the state and decision variables whenever it is clear from the context (for instance conditioned on $I_{t}$ indicates the state and decision variables are for period $t$ ). Let firm $A$ have remnant capacity of $x_{A}$ units, the competitor, $x_{B}$ units left, and the current state of the market be $I_{t}$. Given a competitor's pricing strategy $\mathbf{p}_{B}$ for all states $I$ and capacities $x_{A}, x_{B}$, the firm needs to determine a best-response pricing $\mathbf{p}_{A}$ for all states $I_{t}$ and capacities $x_{A}, x_{B}$.

Since we are considering a multi-period price-setting game, denote, if it exists and is well-defined, which we shall prove shortly, $V_{A}^{\diamond}\left(x_{A}, x_{B}, I_{t+1}\right)$ the equilibrium value function for future periods (with information state $I_{t+1}$, given capacities are $x_{A}, x_{B}$. The superscript $\diamond$ shall represent the unique subgame-perfect equilibrium from now on, provided of course we have shown that such is the case. In contrast, we use the superscript $*$ to represent a firm's optimal best-response value.

Let $V_{A}^{*}\left(p_{B}, x_{A}, x_{B}, I_{t}\right)$ be the best-response value function of $\mathrm{A}$ to price $p_{B}$ offered by firm $\mathrm{B}$ in the state $\left(x_{A}, x_{B}, I_{t}\right)$. Since $\mathbf{p}_{B}$ is given, in the current period firm $B$ will quote $p_{B}=\mathbf{p}_{B}\left(x_{A}, x_{B}, I_{t}\right)$.

$V_{A}^{*}$ is given by the following optimization problem:

$$
\begin{aligned}
V_{A}^{*}\left(\mathbf{p}_{B}, x_{A}, x_{B}, I_{t}\right)= \\
\max _{p_{A}} \operatorname{Pr}\left(\tilde{S}_{I_{t}}=1 \mid I_{t}\right)\left\{P_{A}\left(p_{A}, p_{B}\right)\left(p_{A}+E_{\tilde{I}_{t+1}}\left[V_{A}^{\diamond}\left(x_{A}-1, x_{B}, \tilde{I}_{t+1}\right) \mid I_{t}, \tilde{S}_{I_{t}}=1\right]\right)\right. \\
\quad+P_{B}\left(p_{A}, p_{B}\right) E_{\tilde{I}_{t+1}}\left[V_{A}^{\diamond}\left(x_{A}, x_{B}-1, \tilde{I}_{t+1}\right) \mid I_{t}, \tilde{S}_{I_{t}}=1\right] \\
\left.\quad+\left(1-P_{A}\left(p_{A}, p_{B}\right)-P_{B}\left(p_{A}, p_{B}\right)\right) E_{\tilde{I}_{t+1}}\left[V_{A}^{\diamond}\left(x_{A}, x_{B}, \tilde{I}_{t+1}\right) \mid I_{t}, \tilde{S}_{I_{t}}=1\right]\right\} \\
\quad+\operatorname{Pr}\left(\tilde{S}_{I_{t}}=0 \mid I_{t}\right) E_{\tilde{I}_{t+1}}\left[V_{A}^{\diamond}\left(x_{A}, x_{B}, \tilde{I}_{t+1}\right) \mid I_{t}, \tilde{S}_{I_{t}}=0\right]
\end{aligned}
$$

with the boundary condition $V_{A}^{\diamond}\left(x_{A}, x_{B}, I_{T+1}\right)=0$. Note from this formulation, $E_{\tilde{I}_{t+1}}\left[\cdot \mid I_{t}, \tilde{S}_{I_{t}}=k\right]$, with $k=0,1$, denotes the conditional expectation with respect to $\tilde{I}_{t+1}$ given that the current state is $I_{t}$ and $\tilde{S}_{I_{t}}=k$. We can formulate the best-response value function for firm $B$ in a similar way.

If the best-responses of $A$ and $B$ solving (1) leads to a unique pure-strategy equilibrium (which we show later) in all scenarios of information and capacities, we can substitute $V^{\diamond}(\cdot)$ for $V^{*}(\cdot)$, and proceed to period $t-1$. 


\section{Equilibrium Behavior}

\subsection{Equilibrium Characterization for a duopoly}

In this section, we show the existence of a unique subgame-perfect equilibrium in pure strategies for a duopoly. This is in contrast to the Bertrand-Edgeworth model of price-competition with capacity constraints where a pure strategy equilibrium need not exist. We characterize the equilibrium, which has a simple marginal-value interpretation. For this purpose, we examine the equilibrium conditions backwards, from all information states $I_{T} \in \mathbf{S}_{T}$ first, then $I_{T-1} \in \mathbf{S}_{T-1}$ and so on until $I_{1} \in \mathbf{S}_{1}$.

At $t=T$, given state $I_{T}$, at most one more customer may arrive. If $x_{A}=x_{B}=0$, both firms are stocked out, so that both quotes are $v+1$, and if a customer arrives, it cannot be served. If $x_{A}>0, x_{B}=0$, firm $B$ is stocked out, and hence firm $A$ will quote $p_{A}\left(x_{A}, 0, I_{T}\right)=v$ and sell a unit if a customer arrives. Similarly, if $x_{B}>0, x_{A}=0, p_{B}\left(0, x_{B}, I_{T}\right)=v$. Finally, if $x_{A}>0, x_{B}>0$, for any $p_{B}$, consider $A$ 's decision, given by (1):

$$
\max _{p_{A}} \operatorname{Pr}\left(\tilde{S}_{I_{T}}=1 \mid I_{T}\right) P_{A}\left(p_{A}, p_{B}\right) p_{A}
$$

It is clear that, at optimality, $p_{A}$ should be slightly lower than $p_{B}$ and at most $v$. This is symmetric Bertrand competition with zero variable cost. Thus, in the last period, in this scenario $x_{A}>0, x_{B}>$ 0 , equilibrium exists, is unique, so that $p_{A}=p_{B}=0$.

As a result, under a subgame-perfect equilibrium strategy, necessarily $V_{A}^{\diamond}\left(x_{A}, x_{B}, I_{T}\right)=0$ if $x_{A}>0$ and $x_{B}>0$, or $x_{A}=0$, and $V_{A}^{\diamond}\left(x_{A}, x_{B}, I_{t}\right)=v \operatorname{Pr}\left(\widetilde{S}_{I_{T}}=1\right)$ if $x_{A}>0$ and $x_{B}=0$. As a result, we can analyze equilibrium conditions at $I_{T-1}$.

At $t=T-1$, given a state $I_{T-1}$, if $x_{A}=x_{B}=0$, both firms are stocked out, so that both quotes are $v+1$. If $x_{A}>0, x_{B}=0$, firm $B$ is stocked out and firm $A$ will quote $p_{A}\left(x_{A}, 0, I_{T-1}\right)=v$ and sell a unit to any new customer. Similarly, if $x_{B}>0, x_{A}=0, p_{B}\left(0, x_{B}, I_{T-1}\right)=v$. Finally, if $x_{A}, x_{B}>0$, for any $p_{B}$, A's decision in (1) is slightly more difficult than for the previous period, $T$ :

$$
\begin{aligned}
\max _{p_{A}} \quad \operatorname{Pr}( & \left.\tilde{S}_{I_{T-1}}=1 \mid I_{T-1}\right)\left\{P_{A}\left(p_{A}, p_{B}\right)\left(p_{A}+E_{\tilde{I}_{T}}\left[V_{A}^{\diamond}\left(x_{A}-1, x_{B}, \tilde{I}_{T}\right) \mid I_{T-1}, \tilde{S}_{I_{T-1}}=1\right]\right)\right. \\
& +P_{B}\left(p_{A}, p_{B}\right) E_{\tilde{I}_{T}}\left[V_{A}^{\diamond}\left(x_{A}, x_{B}-1, \tilde{I}_{T}\right) \mid I_{T-1}, \tilde{S}_{I_{T-1}}=1\right] \\
& \left.+\left(1-P_{A}\left(p_{A}, p_{B}\right)-P_{B}\left(p_{A}, p_{B}\right)\right) E_{\tilde{I}_{T}}\left[V_{A}^{\diamond}\left(x_{A}, x_{B}, \tilde{I}_{T}\right) \mid I_{T-1}, \tilde{S}_{I_{T-1}}=1\right]\right\} \\
& +\operatorname{Pr}\left(\tilde{S}_{I_{T-1}}=0 \mid I_{T-1}\right) E_{\tilde{I}_{T}}\left[V_{A}^{\diamond}\left(x_{A}, x_{B}, \tilde{I}_{T}\right) \mid I_{T-1}, \tilde{S}_{I_{T-1}}=0\right]
\end{aligned}
$$

All the terms with $V_{A}^{\diamond}\left(x_{A}, x_{B}, \tilde{I}_{T}\right)$ are zero when $x_{A}, x_{B}>0$, as determined above. If $x_{B}=1$, the expression above can be written as

$$
\max _{p_{A}} \operatorname{Pr}\left(\tilde{S}_{I_{T-1}}=1 \mid I_{T-1}\right)\left(P_{A}\left(p_{A}, p_{B}\right) p_{A}+P_{B}\left(p_{A}, p_{B}\right) E_{\tilde{I}_{T}} v \operatorname{Pr}\left(\tilde{S}_{\tilde{I}_{T}}=1 \mid I_{T-1}, \tilde{S}_{I_{T-1}}=1\right)\right)
$$

The optimal policy is to set $p_{A}$ slightly lower than $p_{B}$ (and at most $\left.v\right)$ if $p_{B}>v \operatorname{Pr}\left(\tilde{S}_{\tilde{I}_{T}}=\right.$ $\left.1 \mid I_{T-1}, \tilde{S}_{I_{T-1}}=1\right)$, and higher than $p_{B}$ otherwise. In other words, firm $A$ has in this case a reservation value of $\operatorname{vPr}\left(\tilde{S}_{\tilde{I}_{T}}=1 \mid I_{T-1}, \tilde{S}_{I_{T-1}}=1\right)$ below which it is not willing to set its price. 
Hence, it will engage in a price war, i.e., Bertrand competition, until the reservation price is reached. If the competitor posts a price below that, it will let the customer go.

On the other hand, if $x_{B} \geq 2, A$ 's decision is

$$
\max _{p_{A}} \operatorname{Pr}\left(\tilde{S}_{I_{T-1}}=1 \mid I_{T-1}\right)\left(P_{A}\left(p_{A}, p_{B}\right) p_{A}\right)
$$

and hence the same logic applies with a reservation price of zero.

Since firm $B$ 's decision has exactly the same structure, any subgame-perfect equilibrium again takes the form of Bertrand competition with a reservation price for each seller, that depends on the existing capacity levels. As before, the best-response value function determined in Equation (1) is well defined for $I_{T-2}$. The same procedure can be continued for lower $t$. To do this, we require the definition the value functions for $A$ and $B$ in a subgame-perfect equilibrium $\left\{\mathbf{p}_{A}^{\diamond}, \mathbf{p}_{B}^{\diamond}\right\}$ : $V_{A}^{\diamond}\left(x_{A}, x_{B}, I_{t}\right):=V_{A}^{*}\left(\mathbf{p}_{B}^{\diamond}, x_{A}, x_{B}, I_{t}\right)$ and $V_{B}^{\diamond}\left(x_{A}, x_{B}, I_{t}\right):=V_{B}^{*}\left(\mathbf{p}_{A}^{\diamond}, x_{A}, x_{B}, I_{t}\right)$. With this notation, we can characterize the structure of any pricing equilibrium.

Lemma 1. For a duopoly, for all $t, I_{t}$, in any subgame-perfect equilibrium, if $x_{A}>0, x_{B}>0$, sellers engage in an asymmetric Bertrand price competition with reservation prices $\min \left\{\triangle V_{A}^{\diamond}\left(x_{A}, x_{B}, I_{t}\right), v\right\}$ for $A$ and $\min \left\{\triangle V_{B}^{\diamond}\left(x_{A}, x_{B}, I_{t}\right), v\right\}$ for $B$, where if $x_{A}, x_{B}>0$

$$
\begin{aligned}
& \triangle V_{A}^{\diamond}\left(x_{A}, x_{B}, I_{t}\right)=E_{\tilde{I}_{t+1}}\left[V_{A}^{\diamond}\left(x_{A}, x_{B}-1, \tilde{I}_{t+1}\right)-V_{A}^{\diamond}\left(x_{A}-1, x_{B}, \tilde{I}_{t+1}\right) \mid I_{t}, \tilde{S}_{I_{t}}=1\right], \\
& \triangle V_{B}^{\diamond}\left(x_{A}, x_{B}, I_{t}\right)=E_{\tilde{I}_{t+1}}\left[V_{B}^{\diamond}\left(x_{A}-1, x_{B}, \tilde{I}_{t+1}\right)-V_{B}^{\diamond}\left(x_{A}, x_{B}-1, \tilde{I}_{t+1}\right) \mid I_{t}, \tilde{S}_{I_{t}}=1\right],
\end{aligned}
$$

and $\triangle V_{A}^{\diamond}\left(x_{A}, 0, I_{t}\right)=\triangle V_{B}^{\diamond}\left(0, x_{B}, I_{t}\right)=\infty$. As a result, in equilibrium, if a customer arrives, the seller with the lowest reservation price sells a unit, at the reservation price of the competitor. If the reservation prices are equal, each one sells a unit with probability 0.5 . Moreover, if $x_{A}=0$ or $x_{B}=0$, the supplier with positive capacity sells a unit at a price $v$.

As a result of the lemma, the value functions $V_{A}^{\diamond}$ and $V_{B}^{\diamond}$ can be defined through a joint recursion. This is presented in the following lemma.

Lemma 2. The value function of an equilibrium for the duopoly is given by the joint recursion $V_{A}^{\diamond}\left(\cdot, \cdot, I_{T+1}\right)=V_{B}^{\diamond}\left(\cdot, \cdot, I_{T+1}\right)=0$, and for all $I_{t}$, for all $x_{A}, x_{B}$,

$$
\begin{aligned}
& V_{A}^{\diamond}\left(x_{A}, x_{B}, I_{t}\right) \\
& = \begin{cases}0 & \text { if } x_{A}=0 \\
\operatorname{Pr}\left(\tilde{S}_{I_{t}}=1 \mid I_{t}\right)\left(v+E_{\tilde{I}_{t+1}}\left[V_{A}^{\diamond}\left(x_{A}-1,0, \tilde{I}_{t+1}\right) \mid I_{t}, \tilde{S}_{I_{t}}=1\right]\right) \\
+\operatorname{Pr}\left(\tilde{S}_{I_{t}}=0 \mid I_{t}\right) E_{\tilde{I}_{t+1}}\left[V_{A}^{\diamond}\left(x_{A}, 0, \tilde{I}_{t+1}\right) \mid I_{t}, \tilde{S}_{I_{t}}=0\right]\end{cases} \\
& \operatorname{Pr}\left(\tilde{S}_{I_{t}}=1 \mid I_{t}\right)\left(\begin{array}{c}
E_{\tilde{I}_{t+1}}\left[V_{A}^{\diamond}\left(x_{A}-1, x_{B}, \tilde{I}_{t+1}\right) \mid I_{t}, \tilde{S}_{I_{t}}=1\right] \\
+\max \left(\triangle V_{A}^{\diamond}\left(x_{A}, x_{B}, I_{t}\right), \triangle V_{B}^{\diamond}\left(x_{A}, x_{B}, I_{t}\right)\right)
\end{array}\right) \\
& +\operatorname{Pr}\left(\tilde{S}_{I_{t}}=0 \mid I_{t}\right) E_{\tilde{I}_{t+1}}\left[V_{A}^{\diamond}\left(x_{A}, x_{B}, \tilde{I}_{t+1}\right) \mid I_{t}, \tilde{S}_{I_{t}}=0\right]
\end{aligned}
$$


and

$$
\begin{aligned}
& V_{B}^{\diamond}\left(x_{A}, x_{B}, I_{t}\right) \\
& = \begin{cases}0 & \text { if } x_{B}=0 \\
\operatorname{Pr}\left(\tilde{S}_{I_{t}}=1 \mid I_{t}\right)\left(v+E_{\tilde{I}_{t+1}}\left[V_{A}^{\diamond}\left(0, x_{B}-1, \tilde{I}_{t+1}\right) \mid I_{t}, \tilde{S}_{I_{t}}=1\right]\right) & \\
+\operatorname{Pr}\left(\tilde{S}_{I_{t}}=0 \mid I_{t}\right) E_{\tilde{I}_{t+1}}\left[V_{A}^{\diamond}\left(0, x_{B}, \tilde{I}_{t+1}\right) \mid I_{t}, \tilde{S}_{I_{t}}=0\right] & \text { if } x_{B}>0, x_{A}=0 \\
\operatorname{Pr}\left(\tilde{S}_{I_{t}}=1 \mid I_{t}\right)\left(\begin{array}{c}
E_{\tilde{I}_{t+1}}\left[V_{B}^{\diamond}\left(x_{A}, x_{B}-1, \tilde{I}_{t+1}\right) \mid I_{t}, \tilde{S}_{I_{t}}=1\right] \\
+\max \left(\triangle V_{A}^{\diamond}\left(x_{A}, x_{B}, I_{t}\right), \triangle V_{B}^{\diamond}\left(x_{A}, x_{B}, I_{t}\right)\right)
\end{array}\right) & \\
+\operatorname{Pr}\left(\tilde{S}_{I_{t}}=0 \mid I_{t}\right) E_{\tilde{I}_{t+1}}\left[V_{A}^{\diamond}\left(x_{A}, x_{B}, \tilde{I}_{t+1}\right) \mid I_{t}, \tilde{S}_{I_{t}}=0\right] & \text { otherwise }\end{cases}
\end{aligned}
$$

where $\triangle V_{A}^{\diamond}\left(x_{A}, x_{B}, I_{t}\right)$ and $\triangle V_{B}^{\diamond}\left(x_{A}, x_{B}, I_{t}\right)$ are defined in Equations (2) and (3).

Joining Lemmas 1 and 2, we find that the subgame-perfect equilibrium exists, and must be unique.

Theorem 1. There exists a unique subgame-perfect equilibrium of the pricing game.

Thus, we characterize the equilibrium prices combining Equations (2) to (5). We can exploit the fact that the recursion is given explicitly, to show some interesting properties of the equilibrium.

Moreover, such an equilibrium has an intuitive explanation: the firm with the lower reservation value always sells at a price that is at most the other firm's reservation value. The concept of a bid-price control is well established and widely used in implementations but usually calculated in a monopoly model - the idea is that the marginal value (at current capacity) sets a price threshold value, above which sales are "admitted", and below which they are "rejected". As the competitive parallel to this, Theorem 1 shows that under competition, a firm should set a bid-price equal to the maximum of its own reservation value and the competitor's reservation value.

\subsection{Equilibrium Prices and Profits}

Since the sellers are symmetric, the value functions are such that $V_{A}^{\diamond}\left(x, y, I_{t}\right)=V_{B}^{\diamond}\left(y, x, I_{t}\right)$, for all $x, y$. As a result, we can simplify the recursion into a single-dimensional recursion.

Lemma 3. For all $x_{A}, x_{B}, I_{t}, V_{A}^{\diamond}\left(x_{A}, x_{B}, I_{t}\right)=W\left(x_{A}, x_{B}, I_{t}\right)$ and $V_{B}^{\diamond}\left(x_{A}, x_{B}, I_{t}\right)=W\left(x_{B}, x_{A}, I_{t}\right)$, where $W\left(\cdot, \cdot, I_{T+1}\right)=0$ and for $t \leq T$, for all $I_{t}, x, y$,

1. $W\left(x, y, I_{t}\right)=-\infty$ if $x<0$ or $y<0$

2. $W\left(0, y, I_{t}\right)=0$

3. for $x>0, y=0$,

$$
\begin{aligned}
& W\left(x, 0, I_{t}\right) \\
& \quad=\operatorname{Pr}\left(\tilde{S}_{I_{t}}=1 \mid I_{t}\right)\left(v+E_{\tilde{I}_{t+1}}\left[W\left(x-1,0, \tilde{I}_{t+1}\right) \mid I_{t}, \tilde{S}_{I_{t}}=1\right]\right) \\
& \quad+\operatorname{Pr}\left(\tilde{S}_{I_{t}}=0 \mid I_{t}\right) E_{\tilde{I}_{t+1}}\left[W\left(x, 0, \tilde{I}_{t+1}\right) \mid I_{t}, \tilde{S}_{I_{t}}=0\right]
\end{aligned}
$$


4. for $x>0, y>0$,

$$
\begin{aligned}
& W\left(x, y, I_{I}\right) \\
& \quad=\operatorname{Pr}\left(\tilde{S}_{I_{t}}=1 \mid I_{t}\right) \\
& \quad \times \max \left\{\begin{array}{l}
E_{\tilde{I}_{t+1}}\left[W\left(x, y-1, \tilde{I}_{t+1}\right) \mid I_{t}, \tilde{S}_{I_{t}}=1\right] \\
E_{\tilde{I}_{t+1}}\left[W\left(y, x-1, \tilde{I}_{t+1}\right)-W\left(y-1, x, \tilde{I}_{t+1}\right)+W\left(x-1, y, \tilde{I}_{t+1}\right) \mid I_{t}, \tilde{S}_{I_{t}}=1\right]
\end{array}\right\} \\
& +\operatorname{Pr}\left(\tilde{S}_{I_{t}}=0 \mid I_{t}\right) E_{\tilde{I}_{t+1}}\left[W\left(x, y, \tilde{I}_{t+1}\right) \mid I_{t}, \tilde{S}_{I_{t}}=0\right]
\end{aligned}
$$

This formulation can in fact be solved in closed-form.

Lemma 4. For all $I_{t}$, if $x<y$,

$$
W\left(x, y, I_{t}\right)=\operatorname{vx} \operatorname{Pr}\left[\tilde{R}_{I_{t}} \geq x+1\right]
$$

In addition, if $x \leq y$,

$$
W(y, x, k)=v E\left[\min \left\{y,\left(\tilde{R}_{I_{t}}-x\right)^{+}\right\}\right]
$$

where $a^{+}=\max \{a, 0\}$.

One of the implications of the lemma is that if $x_{A} \leq x_{B}, \triangle V_{A}^{\diamond}\left(x_{A}, x_{B}, I_{t}\right) \leq \triangle V_{B}^{\diamond}\left(x_{A}, x_{B}, I_{t}\right)$. As a result, the seller with the lowest capacity has the lowest reservation price, and makes the sale if a new customer arrives. This allows us to establish explicitly the equilibrium prices, as we do next.

Theorem 2. For any $I_{t}$, if a new customer arrives, he receives a unit from the seller with the lowest capacity, at a price

$$
v \operatorname{Pr}\left[\tilde{R}_{I_{t+1}} \geq \min \left\{x_{A}, x_{B}\right\} \mid I_{t}, \tilde{S}_{I_{t}}=1\right]
$$

if $x_{A} \neq x_{B}$, i.e., the firms have different capacities. Otherwise, if $x_{A}=x_{B}=x$, the price is

$$
v E\left[\min \left\{1, \tilde{R}_{I_{t+1}}-2 x+2\right\} 1_{\tilde{R}_{I_{t+1}} \geq x} \mid I_{t}, \tilde{S}_{I_{t}}=1\right] .
$$

The theorem shows that prices depend on the capacity of the seller with fewer remaining units. As a result, for a given industry capacity (sum of both firms' capacities), the price is lowest when both have the same amount (symmetric duopoly), in which case it may even be negative. It is highest when one has all of it and the other none (monopoly, in which case, the price is $v$ ). Prices also depend on the forecast of future demand, $\tilde{R}_{I_{t+1}}$, and will be higher if demand is stochastically higher.

Figure 1 illustrates the trajectory of equilibrium prices for one realization of demand (homogeneous over time with arrival probability of 0.05 per period). One observes that, when an arrival occurs, the firm with the lower remaining capacity is the one that sells to the customer. When that occurs, the price posted in the next period increases with a jump, as capacity is depleted, and the reservation values of the two firms increase. Eventually, when the entire capacity of the player with smaller capacity is sold out, the remaining firm takes a monopoly position, and sets a price equal to the customer valuation. In contrast, when no arrival occurs, the price progressively decreases, as the time left before the end of the horizon gets shorter.

Note that, when capacities are equal, the theorem indicates that the equilibrium price might be negative in some cases. This result is at first glance surprising, but is in fact perfectly rational. 

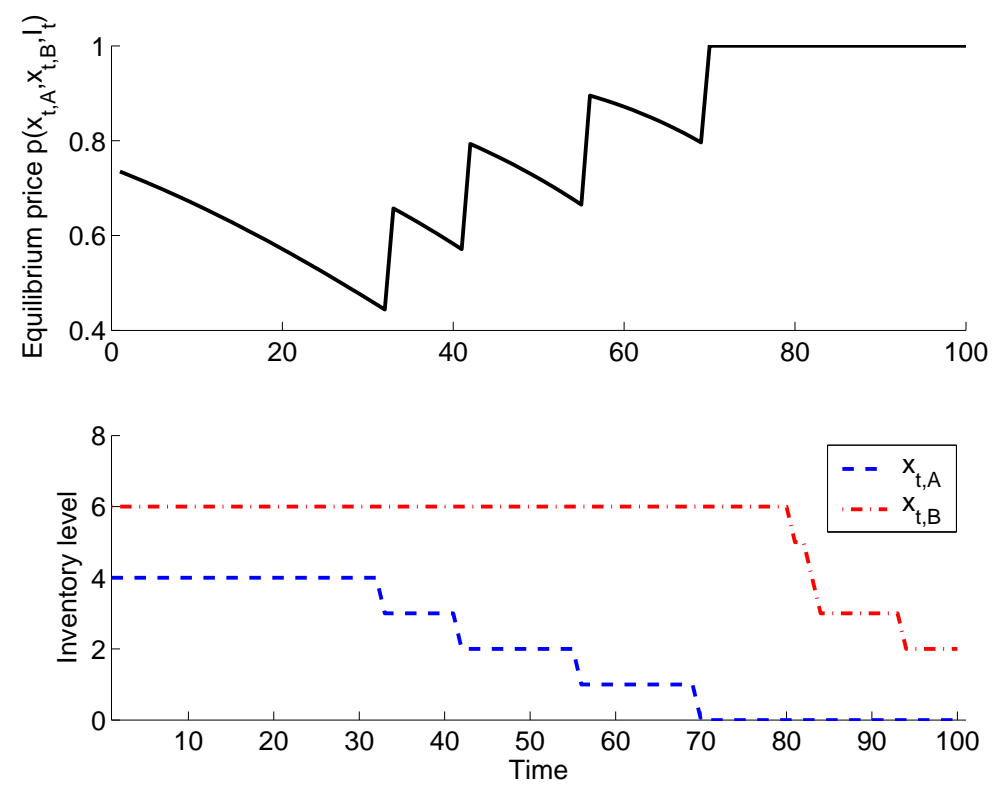

Figure 1: Equilibrium prices for one realization of demand and corresponding trajectory of the remaining capacity. A demand arrival occurs with probability $\theta=0.05$ in each period. The time horizon is $T=100$. We use $v=1$.

Indeed, from Lemma 4 it is easy to see that $W\left(x, x, I_{t}\right) \leq v x \operatorname{Pr}\left[\tilde{R}_{I_{t}} \geq x+1\right]$. Hence, if $W\left(x, x, I_{t}\right) \leq$ $v(x-1) \operatorname{Pr}\left[\tilde{R}_{I_{t}} \geq x\right]$ too, a firm prefers having $x-1$ units of capacity, one less than the competitor. In fact, the pricing dynamics under asymmetric capacities are such that the firm with lower capacity sells all its units before the firm with higher capacity sells its first unit, so that the firm with lower capacity is in a more favorable position. Thus, firms might be willing to pay for becoming the lower-capacity player, which means quoting a negative price.

\subsection{Relation to Dynamic Bertrand-Edgeworth Competition}

The results above hold for general demand processes. One can consider in particular the uncertain market size model, presented at the end of $\S 3.1$, where $\tilde{R}_{I_{t}}=\max \{0, \tilde{M}-t\}$. The prices of Theorem 2 thus become for $x_{A} \neq x_{B}$

$$
v \operatorname{Pr}\left[\tilde{M}-t-1 \geq \min \left\{x_{A}, x_{B}\right\} \mid \tilde{M} \geq t\right]
$$

and for $x_{A}=x_{B}=x$

$$
v E\left[\left\{1-(2 x-\tilde{M}+t)^{+}\right\} 1_{\tilde{M}-t \geq x} \mid \tilde{M} \geq t\right] .
$$

If $\tilde{M}=M$ is deterministic, one can set the number of selling periods $T+1=M$.

Our model thus can be seen as dynamic Bertrand-Edgeworth competition in a stochastic demand setting. Our results hence allow to interpret Dudey [13]'s result as marginal value pricing. Dudey 
shows that there is a unique equilibrium to the finite-stage, deterministic-demand game can best be visualized in Figure 2. The state-space is the 2-dimensional vector of capacities, and at every stage, depending on where this vector falls, the prices are set as shown in the figure; the figure is given with respect to the initial market-size $M$, but the strategies at every period are based on the demand-to-come at period $t$, which as demand is considered known, can be written as $M-t$. Dudey shows uniqueness and equilibrium on a case-by-case basis.

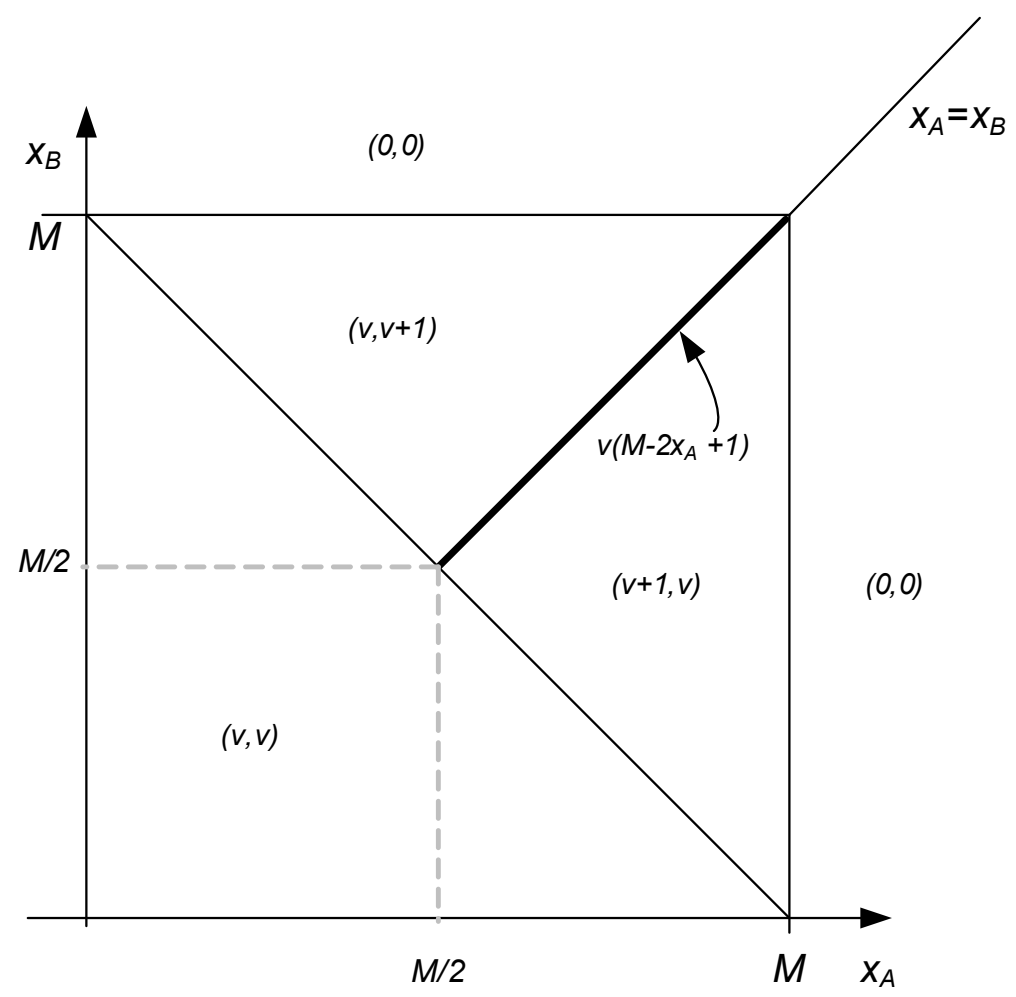

Figure 2: Equilibrium prices at every stage in Dudey [13]. Prices are negative on the thick line.

Our model generalizes Dudey [13], as the prices in Figure 2 are special cases when $M$ is deterministic: When $\min \left\{x_{A}, x_{B}\right\} \geq M-t$ (number of pending customers from $t$ to $T=M-1$ ), the price is zero (marginal cost). When $\min \left\{x_{A}, x_{B}\right\}<M-t$ and $x_{A} \neq x_{B}$, then the price is $v$. When $M-t>x_{A}=x_{B}>(M-t) / 2$, then the price is $v[1-2 x+(M-t)]$. Finally, when $x_{A}=x_{B} \leq(M-t) / 2$, then the price is $v$. Similarly, our Lemma 4 generalizes Dudey's Proposition 2 characterizing equilibrium revenues.

\subsection{Extension to Asymmetric Costs and Time-Varying Customer Valua- tions}

The results presented so far were proved using the fact that (i) the marginal cost of selling a unit was zero; and that (ii) customer valuation was known and identically equal to $v$. Under these two assumptions, Theorem 2 showed that the firm with less capacity will always sell all of its units first and only then the other firm will start selling its capacity. Clearly, the result relies heavily 
on these assumptions. Indeed, if the firm with smaller capacity has a higher marginal cost than its competitor, then it is unlikely that it will sell first when capacity is in excess of supply (since a price war will drive prices to the bottom). Similarly, if the customer valuation is higher towards the end of the horizon (customers arriving late are usually business passengers that are willing to pay more than customers that arrive early), then again the firm with less capacity might prefer to save it for later customers and let the competitor sell first. In this section, we extend the analysis of $\S \S 4.1-4.2$ to include asymmetric costs and time-varying valuations. When valuations decrease over time, Theorem 1 can be extended into Theorem 3. In contrast, when valuations increase, then it is possible that no equilibrium exists, as shown through a counterexample in Theorem 4.

For this purpose, assume that the marginal costs are $c_{A}, c_{B}$ for firms $A, B$ respectively. Also assume that the valuation of a customer arriving at time $t$ given the available information $I_{t}$ is $v_{I_{t}}$.

Theorem 3. When marginal costs are $c_{A}, c_{B}$ and customer valuation $v_{I_{t}}$ decreases over time (i.e., for all sample paths, for all $\left.t, v_{I_{t}} \geq v_{I_{t+1}}\right)$, then there exists a unique subgame-perfect equilibrium of the pricing game.

Thus, existence and uniqueness of equilibrium is guaranteed in this more extended setting. Furthermore, while deriving equilibrium prices analytically becomes quite challenging, some observations can be made about which firm has a lower reservation value in each period. According to Theorem 2, when $c_{A}=c_{B}$, the firm with less capacity sells all of its capacity first. Figure 3 how this observation changes with asymmetric costs, with $c_{A}=0$ and $c_{B}=0,0.3,0.6$. For every cost levels $\left(c_{A}, c_{B}\right)$, one can see that when $x_{B}$ is high enough, A sells first (top-left of the figure); when it is low enough, B sells first (bottom-right). The figure shows the line that separates the two regions. Again, we can see that the firm with much lower capacity tends to sell first. In particular, when $c_{A}=c_{B}=0$, the border between the two regions is the diagonal. As $c_{B}$ increases, the border moves downward, and the region where B sells first becomes smaller. This indicates that a firm has lower reservation value when either its marginal cost is lower, or its capacity level is low enough compared to the competitor's.

In contrast, when valuations increase over time, then the structure of the results changes completely and more than one equilibrium exists.

Theorem 4. Consider the game with two periods $(T=1), v_{I_{0}}=v \in(0,1)$ and $v_{I_{1}}=1, c_{A}=c_{B}=$ 0 . Then there might be more than one subgame-perfect equilibrium in pure strategies.

As a result, the value functions cannot be defined uniquely. This reveals that the variation of valuations over time is critical to ensure that the competitive situation has a well-behaved structure. This is analog to an observation of Davidson and Deneckere [10]: when customers with higher valuations may come late in the sales season, then price competition between two firms will only have equilibria in mixed strategies.

\subsection{Extension to $n \geq 2$ competitors}

One natural question arising from Lemma 1 is whether the competitive dynamics, where each firm has a reservation value below which it is not willing to price, are preserved when the number of firms is larger than two. Indeed, in the duopoly setting, competition occurs à la Bertrand, where price is reduced until all firms but one are willing to sell their capacities. This results in an equilibrium price equal to the reservation value of the "loser", similarly to a second-price auction. We study 


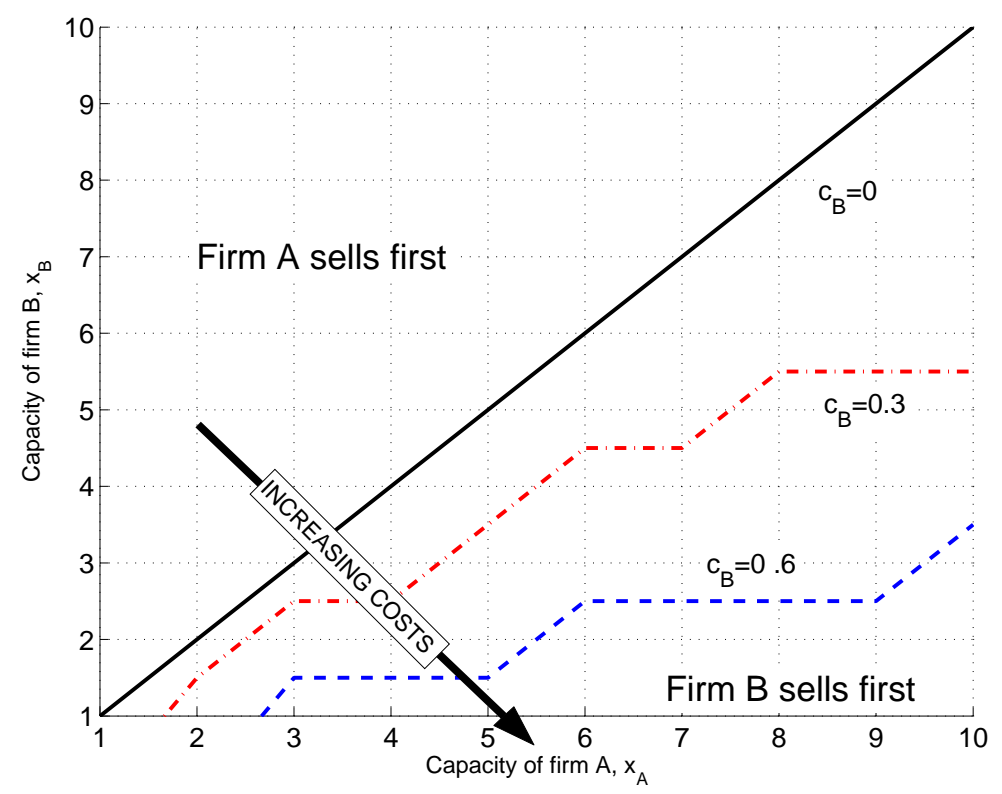

Figure 3: Winning firm as a function of capacities $\left(x_{A}, x_{B}\right)$, with $c_{A}=0$, different values of $c_{B}=$ $0,0.3,0.6$ and $v_{I_{t}}=1$ for all $I_{t}$. A demand arrival occurs with probability $\theta=0.05$ in each period. The time horizon is $T=100$.

next how the results can be extended when the number of competitors is equal to $n \geq 2$. We denote $i=1, \ldots, n$ each one of the firms, instead of $\mathrm{A}$ and $\mathrm{B}$.

In this case, the state is defined as $\mathbf{x}=\left(x_{1}, \ldots, x_{n}\right)$, it becomes $n$-dimensional. Define for all $j$, $\mathbf{e}_{j}$ the vector with all components equal to zero except component $j$ which is equal to 1 .

Given information state $I_{t}$, consider the pricing game for period $t$, assuming that value functions $V_{i}^{\diamond}\left(\mathbf{x}, I_{t+1}\right)$ are well-defined, $i=1, \ldots, n$. Let us analyze the best-response of two firms $i$ and $j$. Since again valuations are constant, equal to $v$, all firms are willing at sell at $v$. To build intuition, assume first that all firms except $j$ price higher than $v$. Let

$$
V_{i, j}\left(I_{t}\right):=E_{\tilde{I}_{t+1}}\left[V_{i}^{\diamond}\left(\mathbf{x}-\mathbf{e}_{i}, \tilde{I}_{t+1}\right) \mid I_{t}, \tilde{S}_{I_{t}}=1\right]
$$

Firm $i$ will choose to undercut $j$ 's price, denoted $p$, if and only if

$$
p+V_{i, i} \geq V_{i, j}
$$

Similarly, $j$ will be willing to reduce its price below $p$ if and only if

$$
p+V_{j, j} \geq V_{j, i}
$$

Hence, if $V_{i, j}-V_{i, i}<V_{j, i}-V_{j, j}$ then $i$ will be able to price below $j$; if $V_{i, j}-V_{i, i}>V_{j, i}-V_{j, j}$, the reverse will be true; finally, if $V_{i, j}-V_{i, i}=V_{j, i}-V_{j, j}$ both firms will reach the same price and will serve the customer with equal probability. More generally, when $n$ players are active in this price competition, if for all $j \neq i, V_{i, j}-V_{i, i} \leq V_{j, i}-V_{j, j}$, then $i$ will offer the lowest price and sell to the customer. It turns out that such a relationship exists: if there is a unique firm with capacity higher 
than its competitors, then such $i$ is any of the remaining firms; if there are two or more firms with the highest level of capacity, then $i$ is one of these. This allows us to prove the general equilibrium structure.

Theorem 5. When there are $n$ firms with capacities $\mathbf{x}$, then there exists a unique subgame-perfect equilibrium of the pricing game. The equilibrium can be described as follows. Let $x_{\max }=\max _{j} x_{j}$ and $M=\left\{i \mid x_{i}=x_{\max }\right\}$.

- If $|M|=1$, then the equilibrium price is

$$
v \operatorname{Pr}\left[\tilde{R}_{I_{t+1}} \geq \sum_{j} x_{j}-x_{\max } \mid I_{t}, \tilde{S}_{I_{t}}=1\right]
$$

and some firm $j \notin M$ sells to the customer.

- If $|M| \geq 2$, then the equilibrium price is

$$
v E\left[\min \left\{1, \tilde{R}_{I_{t+1}}-\sum_{j} x_{j}+2\right\} 1_{\tilde{R}_{I_{t+1}} \geq \sum_{j} x_{j}-x_{\max }} \mid I_{t}, \tilde{S}_{I_{t}}=1\right]
$$

and a firm $i \in M$ sells to the customer.

The theorem thus generalizes Theorem 2 to an oligopolistic industry structure. We observe that again it is possible to find negative prices in equilibrium. This occurs when there are at least two firms with the largest industry capacity. In that case, one of them offers a very low price in order to exit the group of firms with the largest capacity, which will sell last. In all other cases, when the largest firm is unique $(|M|=1)$, the smaller firms sell their capacities first, at a price given by the capacity of all players except the largest one. Hence, prices are independent on how capacity is shared among small firms, and is set by the reservation value of the largest firm.

Since the structure of the equilibrium has been established, it is possible to compare the level of profits in the industry for a given level of aggregate capacity. This is presented in the next theorem.

Theorem 6. Denote $V_{\text {industry }}\left(\mathbf{x}, I_{t}\right)=\sum_{i=1}^{n} V_{i}^{\diamond}\left(\mathbf{x}, I_{t}\right)$ and $\sum_{i=1}^{n} x_{i}=n$. Then,

$$
\begin{aligned}
& \frac{V_{\text {industry }}\left((1, \ldots, 1), I_{t}\right)}{n}=v E\left[\min \left\{1,\left(\tilde{R}_{I_{t}}-(n-1)\right)^{+}\right\} \mid I_{t}\right] \\
\leq & \frac{V_{\text {industry }}\left(\mathbf{x}, I_{t}\right)}{n}\left((n, 0, \ldots, 0), I_{t}\right) \\
\leq & \frac{V_{\text {industry }}\left((n, \ldots)\left[\min \left\{1, \frac{\tilde{R}_{I_{t}}}{n}\right\} \mid I_{t}\right] .\right.}{n}=v E
\end{aligned}
$$

Not surprisingly, the highest level of industry profit is reached by the monopoly. This is intuitive, because, by eliminating competition, a monopoly is able to set a price equal to $v$ for the entire horizon. At the other end of the spectrum, the lowest profit is achieved by a completely fragmented industry where all players have a capacity equal to one. 
Allen and Hellwig [1] study the behavior of Bertrand-Edgeworth equilibria for general demand functions when there are $n$ firms and each firm is small relative to the market as a whole (mixed strategy equilibria are known to exist, as shown in [9]). Their main result is that as $n \rightarrow \infty$ for fixed capacities, the prices approach perfectly competitive prices almost surely. Our result in Theorem 6

closely parallels this. Indeed, $V_{\text {industry }}\left((1, \ldots, 1), I_{t}\right)$ tends to 0 whenever the demand is fixed and $n$ is made larger.

\section{Implications of Dynamic Competition}

The results derived until now fully characterize the equilibrium, for a duopoly and a general oligopoly. While the model is simplified along certain dimensions (such as assuming fixed valuations), the advantage is that we obtain a unique subgame-perfect equilibrium in a game of multi-period competition. This allows us to explore a number of strategic issues surrounding price competition.

\subsection{Prediction of Negative Prices}

The model predicts negative prices (prices below the marginal cost, taken here to be zero). In practice, many low-cost carriers price extremely low; Ryanair in Europe for instance, has offered round-trip fares starting at $£ 0.01$ (not including taxes-Ryanair current web site shows many seats at $£ 5.00$ all-inclusive, changed after a EU ruling on price announcements). If one supposes that the airline plans to recover its fixed cost over all the passengers, then this is clearly below the average cost per passenger.

However, often one does not see negative prices. This might be for a number of reasons.

1. Firms do not have equal capacities, cannot observe each other's capacities, or assign a very low probability that they are the same.

2. Firms' marginal costs are not zero, and negative prices are then shifted up.

3. Firms' products are differentiated to some degree, either because of different airports or different departure times.

4. More generally, any of the assumptions behind the model is violated, and either we do not have an equilibrium any more, or a completely different equilibrium appears.

5. The observational requirements of an equilibrium do not hold or firms do not optimize given the information. We elaborate further on this in the next section.

Of course, our model, similar to Bertrand's, studies an idealized model of competition in a dynamic setting with stochastic market demand. While negative prices are odd, they are perfectly rational - the same way that the Bertrand's paradox is odd but rational, and the Prisoner's dilemma is suboptimal but logical.

\subsection{Observational Requirements}

In practice each firm observes the (publicly posted) market price of the competitor but not the competitor's current capacity. The firms' best-response functions however are based on full infor- 
mation of the purchases and capacities. While the concept of equilibrium itself is independent of such observability (the equilibrium can be thought of defined for an omniscient third-party ) it calls into question whether two firms reacting to each other's strategy will ever be able to reach such an equilibrium. We point out here, that even though one normally does not observe a customer purchasing at the other firm, whenever such a purchase occurs, the price spikes upwards momentarily (see Figure 4). So the information, in our model with known valuations, is completely coded in the price paths. So the firm monitoring the market price, knows precisely how many customers have arrived and purchased at the competing firm, and thereby infer, knowing the initial capacity, the state of the competitor's capacity. Using the same observations, firms can arrive at a joint forecast quickly as the arrivals over a certain initial period can be used to forecast the rate accurately.

\subsection{Effect of Capacity Split and Market Size}

Our model highlights that the ratio of capacities to market-size plays a critical role in the degree of price competition and revenues obtained. To obtain some insight, we show some sample price-paths in Figure 4, when the probability of an arrival per period is constant. The figure illustrates price and capacity paths for initial capacities $\left(x_{0, A}, x_{0, B}\right)=(15,20)$ or $(20,20)$, and expected demand equal to 15 or 20 (i.e., the probability of an arrival per period is 0.15 and 0.2 respectively, since there are 100 periods). There are two things to note about the price-paths. When the capacities are not identical, and demand is moderately high, prices are relatively high and firms make significant profits, in contrast to the Bertrand's paradox. When capacities are identical, even if the demand is higher than the combined capacity in the market, firms compete fiercely initially to lower their capacity and get the right to sell first and take less risk on their capacity. The equilibrium price is hence negative in the beginning. In addition, when one of the firms exhausts its capacity, then the equilibrium price jumps up to the valuation of the customer, $v=1$.

To capture better the insights from the sample paths, Figure 5 shows the starting market price at time 0 , as a function of the market demand (expected number of customers during the horizon) and for different share of capacity between the firm, the total being fixed. Except for the degenerate case of equal capacities, firms set prices approaching collusive prices, especially when the market demand is high compared to the total capacity. Figure 6 shows the total industry profits as a function of market demand.

\subsection{Capacity Choice and Entry Decisions}

Lemma 4 characterizes the profit of the firm in equilibrium. Each firm's profit is non-monotonic in its own capacity. More importantly, consider that there is an incumbent in the market with a fixed capacity that it cannot change. A natural question is to determine the capacity choice for a new entrant. Figure 7 shows a firm's revenue at the best capacity point, given the incumbent's capacity.

One can see that one's best-response profit is non-monotonic. This indicates that a firm achieves the highest profit when the competitor either has a very small capacity, or a very large one. This has important implications regarding the capacity game that firms might play before entering into the dynamic price competition phase.

Kreps and Scheinkman [23] conjecture that their results do not hold when there is uncertainty in the aggregate demand. This subsequently has been investigated in a number of articles, but usually only with a static second-stage pricing game, with some papers assuming demand is revealed prior to 

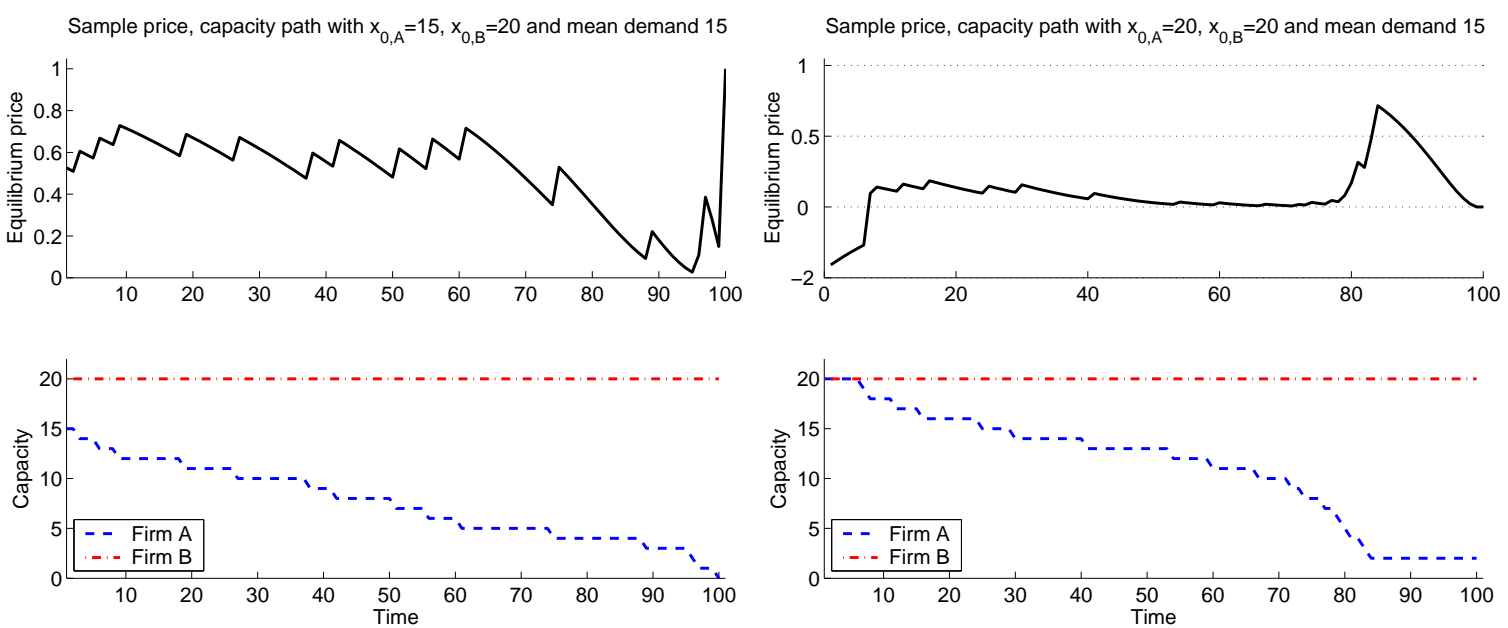

Sample price, capacity path with $x_{0, A}=15, x_{0, B}=20$ and mean demand 20

Sample price, capacity path with $\mathrm{x}_{0, \mathrm{~A}}=20, \mathrm{x}_{0, \mathrm{~B}}=20$ and mean demand 20
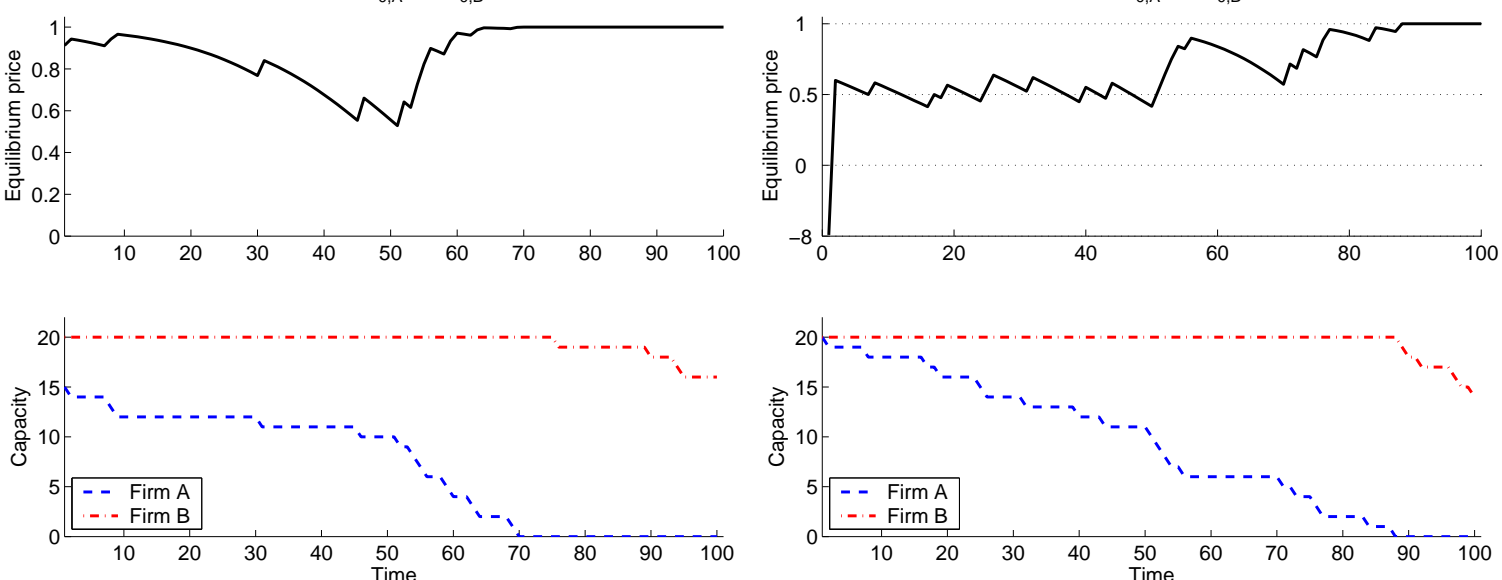

Sample price, capacity path with $x_{0, A}=20, x_{0, B}=20$ and mean demand 40
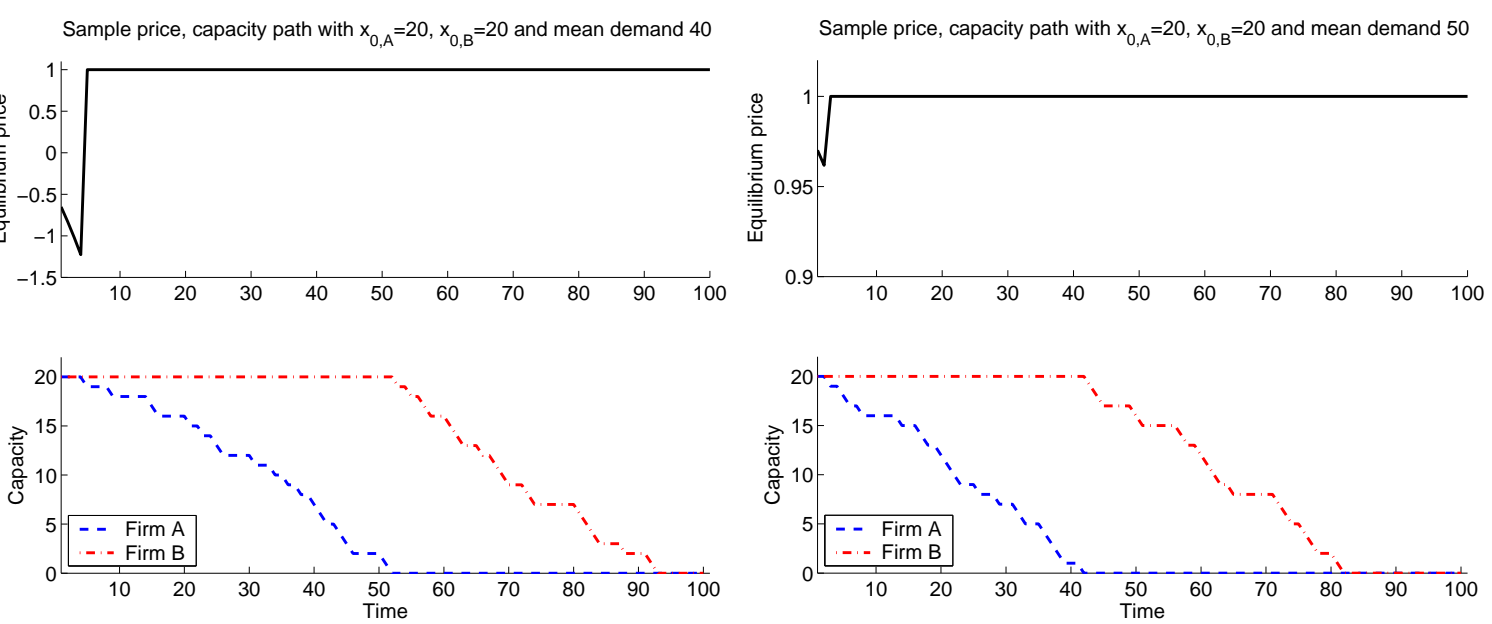

Figure 4: Sample price and inventory paths for two capacity combinations $(15,20)$ and $(20,20)$, and demand equal to 15 (top) and 20 (middle). The bottowm figures illustrate that prices can be low when capacities are identical, even when total demand exceeds aggregate capacity. 


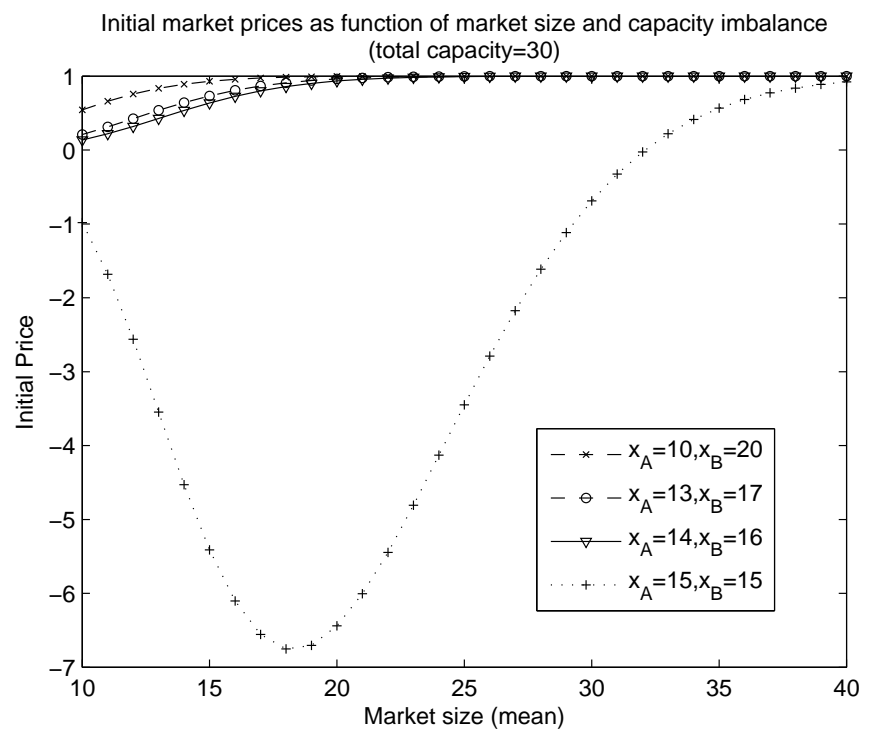

Figure 5: Initial prices as a function of market demand for different values of capacities.

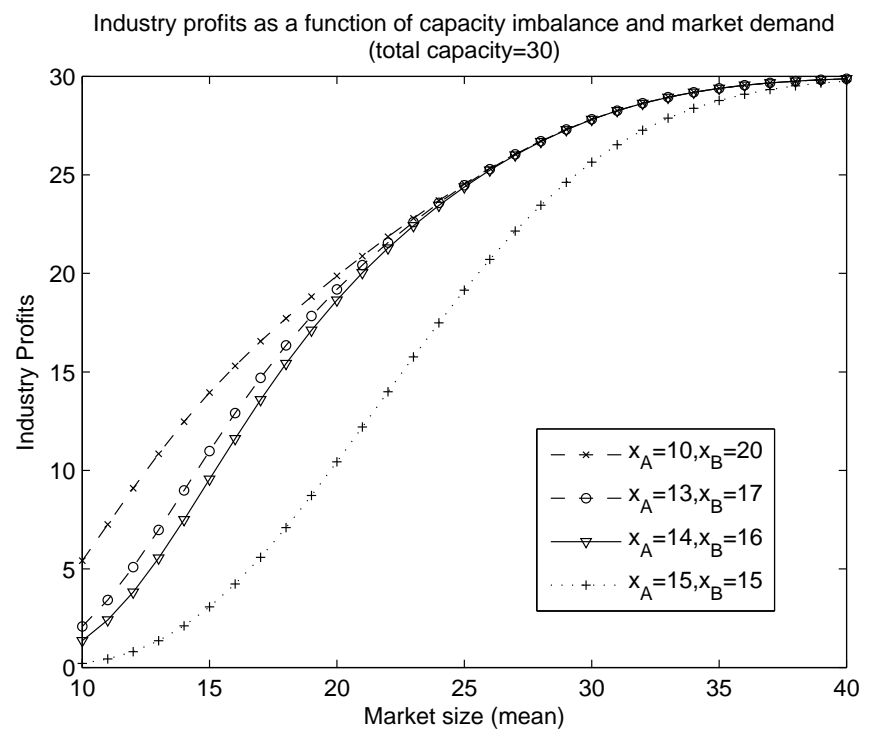

Figure 6: Total industry profits as a function of market demand for different ratios of capacities. 


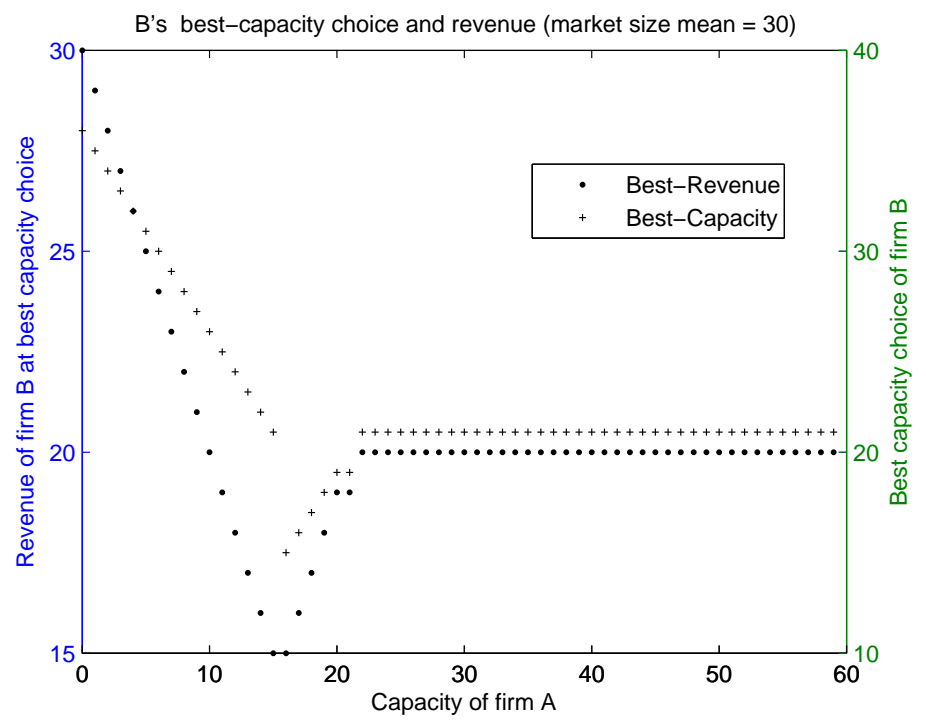

Figure 7: Revenue and best capacity choice of an entrant, as a function of the incumbent's capacity.

the second stage game. Gal-Or [16] considers the case with inelastic demand (as we do in this paper) with both demand and price set before demand realization. Hviid ([22], [21]) considers the problem with uncertainty in the market-size before capacity choice that resolves during the pricing stage. In Lepore [24] firms observe demand after setting capacities. With a demand model quite similar to ours, de Frutos and Fabra [12] consider price-inelastic demand with uncertain aggregate market size and study the two-stage game under various scenarios of demand realization. The conclusion in all these papers is either the model lacks a pure-strategy equilibrium or that in equilibrium the first-stage capacities can potentially be far from the Cournot outcomes. Osborne and Pitchuk [30] study a duopoly with an adversarial rationing rule and characterize regions of the capacity space with pure or mixed-strategy equilibria. They find that the equilibrium prices are lower the smaller the demand compared to capacity. Osborne and Pitchuk [30] on the other hand confirm, under their adversarial rationing, and a more general demand model, that the capacity choice coincides with Cournot predictions. Allen and Hellwig [1] study the same problem, and likewise find mixed strategy equilibria and show that duopoly prices never exceed competitive prices (the prices that clear the market). They, as in almost all the static Bertrand-Edgeworth models, have to make an assumption on spill, and their results are assuming proportional rationing.

Notice that with dynamic competition one does not need to specify the rationing rule as each customer is modeled individually as choosing the lowest priced product in that period, side-stepping one of the problems with static price competition - the non-robustness of the results when one considers a different rationing rule as that of [23]. Of course, the order in which the customers are assumed to arrive (even if this is stochastic) is in some way a rationing rule, but (i) one has some physical evidence that customers do come in a certain way (say Poisson; or, in the RM context, business customers closer to departure) and one can hopefully test the assumptions empirically, and (ii) if we assume that all customers have the same valuation, rationing does not matter, making our conclusions more robust.

Dudey [13] considers the equivalent of the Kreps and Scheinkman [23] game - capacity choice and 
then pricing - for his model, where the second-stage game is a dynamic pricing game, and shows that this two-stage game has equilibria: if $M$ is odd, then the firms choose $\frac{M+1}{2}, \frac{M-1}{2}$ in any equilibrium, and if $M$ is even, both firms choose $\frac{M}{2}$, and all consumers pay the monopoly price. While equilibrium exists, its nature is qualitatively different than the one in Kreps and Scheinkman [23], where Cournot outcomes result, with prices well below monopoly prices.

In contrast, when we add uncertainty to the market size, we find that an equilibrium for the capacity choice can fail to exist, see Figure 8, a fact widely observed in the literature of the two-stage games $([22],[21])$.

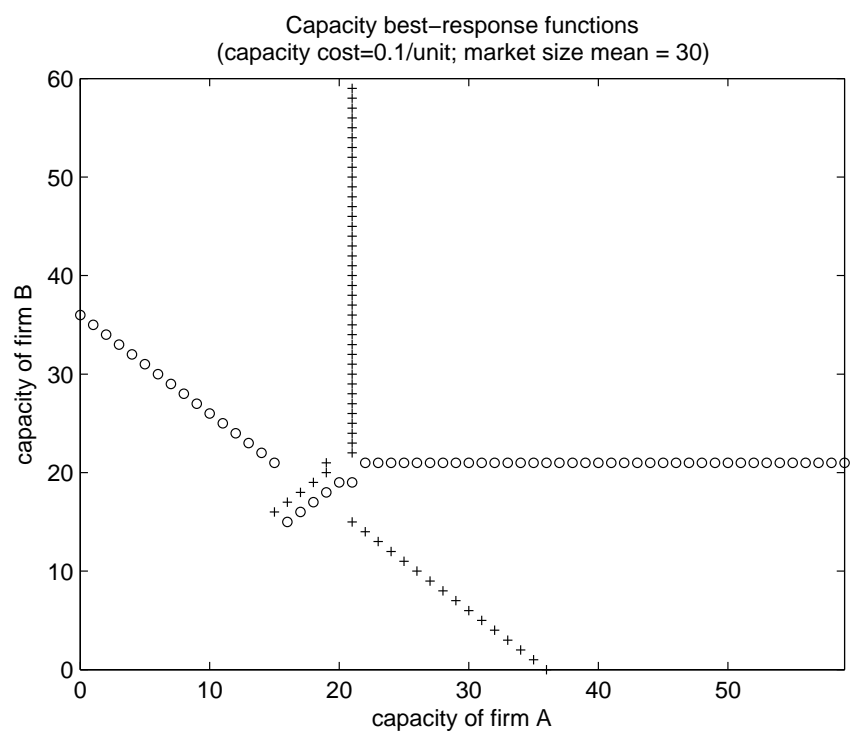

Figure 8: Capacity best-response functions, for a capacity cost of $0.1 /$ unit and an average market size equal to 30 .

\section{Conclusions and Further Research}

In this paper, we study dynamic price competition between two firms with fixed capacities that compete to satisfy a stochastic demand that arrives over time. We show that subgame-perfect equilibrium exists and is unique. The equilibrium pricing can be characterized by a simple "competitive bid-price" type of rule: each firm calculates a competitive (equilibrium) reservation value, and in each period, the firm with the lower reservation value makes the sale at a price equal to the other firm's reservation value. In addition, we show that in equilibrium the lower-capacity firm will always sell its entire capacity before the competitor starts selling at all. As a result, the lower-capacity firm generates its profits by selling its units with higher probability, but at a lower price (because it must reduce its price to be able to sell the capacity). The higher-capacity firm, on the other hand, sells its units with lower probability, but at the highest price, since by the time it sells, the competitor has exhausted its capacity. Lower prices arise purely out of competitive forces, and not for price-discrimination purposes. On the other hand, the prices are not as low as predicted by the static Bertrand game in equilibrium. 
We then extend the basic model to non-zero capacity costs and non-stationary customer valuations. We find that our results are robust provided that customer valuations are non-increasing over time, in which case, equilibrium may not be unique anymore. We also extend the model to more than two firms.

The existence and uniqueness result allows us to provide some insights into the nature of competition. We investigate the evolution of equilibrium prices and the corresponding equilibrium profits. We highlight how the capacity split between firms and the market to capacity ratio affect prices and profits. Finally, we consider the capacity choice decision and find that there may be no pure-strategy equilibrium with uncertain market sizes.

While stylized, the model gives managers insight into dynamic pricing competition with limited capacities, and the role of capacities in determining the degree of competition. The simple decision rule identified in the paper considers competitor's pricing reactions, one of the features that is missing in most RM implementations. Finally, the model can also be used to evaluate capacity entry decisions, specifically how the capacity decision interacts with subsequent price competition.

The model opens a number of research questions for further study. For example, we identified that the assumptions regarding customer valuations (and how these evolve over time) are critical for the existence and uniqueness of equilibrium. It would thus be interesting to explore what dynamic pricing strategies are appropriate under competition when customer valuation increases over time. This is especially relevant for the airline industry, where customers arriving late tend to be business customers willing to pay more for a seat. In addition, it is also worth studying how the results identified in this paper change when customers have unknown valuations, i.e., when the probability of selling a unit is decreasing in the price quoted. This model also reflects the behavior of pricesensitive customers.

Our model assumes that capacities are observable, and later argues that they can be inferred perfectly from the price path. However, when one cannot guarantee a unique equilibrium, then what one can observe and infer determines a firm's best response. Operationally, this is one of the critical research questions that has to be resolved before one can make these economic and game theory concepts implementable for operational use.

\section{References}

[1] B. Allen and Hellwig. Bertrand-edgeworth oligopoly in large markets. Review of Economic Studies, 53:175-204, 1986.

[2] S. P. Anderson, A. de Palma, and J-F. Thisse. Discrete-Choice Theory of Product Differentiation. MIT Press, Cambridge, MA, 1992.

[3] S. P. Anderson and Y. Schneider. Price competition with revenue management and costly consumer search. Technical report, University of Virginia, Department of Economics, Charlottesville, VA, December 2007.

[4] J. Bertrand. Theorie math ématique de la richesse sociale. Journal des Savants, pages 499-508, 1983.

[5] G. Biglaiser and N. Vettas. Dynamic price competition with capacity constraints and strategic buyers. Technical report, Department of Economics, University of North Carolina, http://www.unc.edu/ gbiglais/, 2004. 
[6] E. Chamberlin. The Theory of Monopolistic Competition. Harvard University Press, Cambridge, MA, 1933.

[7] P. K. Chintagunta and V. R. Rao. Pricing strategies in a dynamic duopoly: A differential game model. Management Science, 42:1501-1514, 1996.

[8] A. Cournot. Recherches sur les Principes Mathématiques de la Théorie des Richesses. (English Version) Macmillan, Paris, France, 1838.

[9] P. Dasgupta and E. Maskin. The existence of equilibria in discontinuous economic games, i: Theory. Review of Economic Studies, 53:1-26, 1986.

[10] C. Davidson and R. Deneckere. Long-run competition in capacity, short-run competition in price and the Cournot model. RAND Journal of Economics, 17:404-415, 1986.

[11] M. A. De Francesco and S. Neri. Bertrand-edgeworth games under oligopoly with a complete characterization for the triopoly. Technical report, University of Siena, "http://mpra.ub.unimuenchen.de/10767/", 2008.

[12] M-A. de Frutos and N. Fabra. Endogenous capacities and price competition: The role of demand uncertainty. Technical report, Universidad Carlos III de Madrid, Madrid, Spain, http://www.eco.uc3m.es/ nfabra/, 2009.

[13] M. Dudey. Dynamic Edgeworth-Bertrand competition. Quarterly Journal of Economics, 107:1461-1477, November 1992.

[14] F. Y. Edgeworth. Papers relating to political economy. Macmillan, London, U.K., 1925.

[15] D. Fudenberg and J. Tirole. Game Theory. MIT Press, Cambridge, MA, 1991.

[16] E. Gal-Or. Price dispersion with uncertain demand. International Economic Review, 25:441$457,1984$.

[17] G. Gallego and M. Hu. Dynamic pricing of perishable assets under competition. Technical report, Rotman School of Management, University of Toronto, "http://www.rotman.utoronto.ca/facbios/file/crm_r2b.pdf", 2008.

[18] G. Gallego, T. Huh, W. Kang, and R. Phillips. Price competition with the attraction demand model: Existence of unique equilibrium and its stability. Manufacturing and Service Operations Management, 8:359-375, 2006.

[19] G. Gallego and G. J. van Ryzin. Optimal dynamic pricing of inventories with stochastic demand over finite horizons. Management Science, 40:999-1020, 1994.

[20] D. Hirata. Bertrand-edgeworth equilibrium in oligopoly. Technical report, University of Tokyo, "http://mpra.ub.uni-muenchen.de/7946/", 2008.

[21] M. Hviid. Sequential capacity and price choices in a duopoly model with demand uncertainty. Journal of Economics, 51(2):121-144, 1990.

[22] M. Hviid. Capacity constrained duopolies, uncertain demand and non-existence of pure strategy equilibria. European Journal of Political Economy, 7:183-190, 1991.

[23] D. Kreps and J. Scheinkman. Quantity precommitment and Bertrand competition yield Cournot outcomes. Bell Journal of Economics, 14:326-337, 1983. 
[24] J. J. Lepore. Cournot outcomes under bertrand-edgeworth competition with demand uncertainty. Technical report, California Polytechnic State University, Orfalea College of Business, CA, USA, http://buiznt.cob.calpoly.edu/cob/econ/jlepore/research.html, 2008.

[25] Y. Levin, J. McGill, and M. Nediak. Dynamic pricing in the presence of strategic consumers and oligopolistic competition. Management Science, 55(1):32-46, 2009.

[26] R. Levitan and M. Shubik. Price duopoly and capacity constraints. International Economic Review, 13:111-122, 1972.

[27] M. Z. F. Li, A. Zhang, and Y. Zhang. Airline seat alloction competition. International Transactions in Operational Research, 15:439-459, 2008.

[28] T. Mizuno. On the existence of a unique price equilibrium for models of product differentiation. International Journal of Industrial Organization, 21:761-793, 2003.

[29] S. Netessine and R. A. Shumsky. Revenue management games. Technical report, W. E. Simon Graduate School of Business Administration, University of Rochester, Rochester, NY, 2000.

[30] M. J. Osborne and C. Pitchik. Price competition in a capacity-constrained duopoly. Journal of Economic Theory, 38:238-260, 1986.

[31] G. Perakis and A. Sood. Competitive multi-period pricing with fixed inventories. Technical report, MIT, "http://dspace.mit.edu/handle/1721.1/3880", 2004.

[32] R Phillips. Pricing and Revenue Optimization. Stanford Business Books, Stanford, CA, 2005.

[33] K. T. Talluri. On equilibria in duopolies with finite strategy spaces. Technical Report WP-701, UPF, 2003.

[34] K. T. Talluri and G. J. van Ryzin. The Theory and Practice of Revenue Management. Kluwer, New York, NY, 2004.

[35] X. Zhao. Competitive supply chain and revenue management: Four essays. Ph.d, University of British Columbia, Vancouver, Canada, June 2003. 


\section{Appendix: Proofs}

\section{Proof of Lemma 1}

$\underline{\text { Proof }}$

If $x_{A}>0, x_{B}>0$, if $p_{B}>v$, it is clear that $A$ should price at $v$, because this is the highest it will ever obtain from a customer. If $p_{B} \leq v$, firm $A$ faces the problem in Equation (1), or equivalently,

$$
\begin{aligned}
\max _{p_{A}} \quad E_{\tilde{I}_{t+1}}[ & P_{A}\left(p_{A}, p_{B}\right)\left(p_{A}+V_{A}^{\diamond}\left(x_{A}-1, x_{B}, \tilde{I}_{t+1}\right)\right) \\
& \left.+P_{B}\left(p_{A}, p_{B}\right) V_{A}^{\diamond}\left(x_{A}, x_{B}-1, \tilde{I}_{t+1}\right) \mid I_{t}, \tilde{S}_{I_{t}}=1\right]
\end{aligned}
$$

Firm $A$ is better off pricing $p_{A}<p_{B}$ if $\left.p_{B}+E\left[V_{A}^{\diamond}\left(x_{A}-1, x_{B}, \tilde{I}_{t+1}\right)\right]>E\left[V_{A}^{\diamond}\left(x_{A}, x_{B}-1, \tilde{I}_{t+1}\right)\right)\right]$ (conditional expectation). Thus, the best-response of $A$ is to price slightly below $p_{B}$, until the reservation price $\triangle V_{A}^{\diamond}\left(x_{A}, x_{B}, I_{t}\right)$ is reached. The same is true for $B$. As a result, the sellers engage in Bertrand price competition and the equilibrium is well-known to be that the seller with the lowest reservation price sells a unit, at the highest reservation price.

Q.E.D

\section{Proof of Lemma 2}

\section{$\underline{\text { Proof }}$}

The recursion is immediate after applying the structure in equilibrium, derived in Lemma 1 , into Equation (1). In the case where $x_{A}>0, x_{B}>0$, we use the fact that both $\triangle V_{A}^{\diamond}\left(x_{A}, x_{B}, I_{t}\right)$ and $\triangle V_{B}^{\diamond}\left(x_{A}, x_{B}, I_{t}\right)$ must be smaller than $v$, since if a firm's competitor picks a price larger than $v$, it is always in the firm's interest to set the price at $v$. Thus, its reservation value must be lower. Q.E.D

\section{Proof of Theorem 1}

$\underline{\text { Proof }}$

First, Lemmas 1 and 2 show that, if equilibrium exists, it is unique. In addition, since the value functions are well-defined, existence follows from the existence of equilibrium in asymmetric Bertrand competition, established in Lemma 1.

Q.E.D

\section{Proof of Lemma 3}

$\underline{\text { Proof }}$

The transformation of $V_{A}^{\diamond}, V_{B}^{\diamond}$ is direct from Equations (4) and (5).

Q.E.D 


\section{Proof of Lemma 4}

\section{$\underline{\text { Proof }}$}

We show the result by induction, for $t=T, T-1, \ldots$, for all values of $I_{t}, x, y$.

At $t=T+1$, it is clearly true since $W\left(\cdot, \cdot, I_{T+1}\right)=0$.

Assume that the expressions in the lemma are true for $t+1$, i.e.

- if $0 \leq x<y, W\left(x, y, I_{t+1}\right)=\operatorname{vx} \operatorname{Pr}\left[\tilde{R}_{I_{t+1}} \geq x+1 \mid I_{t+1}\right]$;

- if $0 \leq x \leq y, W\left(y, x, I_{t+1}\right)=v E\left[\min \left\{y,\left(\tilde{R}_{I_{t+1}}-x\right)^{+}\right\} \mid I_{t+1}\right]$.

If $x=0$, we solve the monopoly case, where the value function is clearly $W\left(0, y, I_{t}\right)=v E\left[\min \left\{y, \tilde{R}_{I_{t}}\right\} \mid I_{t}\right]$. Consider $1 \leq x<y$. In that case, we have that

$$
\begin{aligned}
& W\left(y, x-1, I_{t+1}\right)-W\left(y-1, x, I_{t+1}\right) \\
& \quad=v E\left[\min \left\{y,\left(\tilde{R}_{I_{t+1}}-x+1\right)^{+}\right\}-\min \left\{y-1,\left(\tilde{R}_{I_{t+1}}-x\right)^{+}\right\} \mid I_{t+1}\right] \\
& \quad=v \operatorname{Pr}\left[\tilde{R}_{I_{t+1}} \geq x \mid I_{t+1}\right] .
\end{aligned}
$$

Also, since $W\left(x, x, I_{t+1}\right)=v E\left[\min \left\{x,\left(\tilde{R}_{I_{t+1}}-x\right)^{+}\right\} \mid I_{t+1}\right] \leq v x \operatorname{Pr}\left[\tilde{R}_{I_{t+1}}-x \geq 0 \mid I_{t+1}\right]$

$$
\begin{aligned}
& W\left(x, y-1, I_{t+1}\right)-W\left(x-1, y, I_{t+1}\right) \\
& \leq v x \operatorname{Pr}\left[\tilde{R}_{I_{t+1}} \geq x+1 \mid I_{t+1}\right]-v(x-1) \operatorname{Pr}\left[\tilde{R}_{I_{t+1}} \geq x \mid I_{t+1}\right] \\
& \quad \quad \text { where the inequality is applied in the case } x=y-1, \\
& =v x \operatorname{Pr}\left[\tilde{R}_{I_{t+1}} \geq x \mid I_{t+1}\right]-v x \operatorname{Pr}\left[\tilde{R}_{I_{t+1}}=x \mid I_{t+1}\right] \\
& \quad \quad-v(x-1) \operatorname{Pr}\left[\tilde{R}_{I_{t+1}} \geq x \mid I_{t+1}\right] \\
& =v \operatorname{Pr}\left[\tilde{R}_{I_{t+1}} \geq x \mid I_{t+1}\right]-v x \operatorname{Pr}\left[\tilde{R}_{I_{t+1}}=x \mid I_{t+1}\right] \\
& \leq W\left(y, x-1, I_{t+1}\right)-W\left(y-1, x, I_{t+1}\right)
\end{aligned}
$$

As a result, the firm with higher capacity $y$ sets the reservation value, equal to

$$
E_{\tilde{I}_{t+1}}\left\{W\left(y, x-1, \tilde{I}_{t+1}\right)-W\left(y-1, x, \tilde{I}_{t+1}\right) \mid I_{t}, \tilde{S}_{I_{t}}=1\right\} .
$$

The recursion of Equation (7) can thus be rewritten as

$$
\begin{aligned}
W( & \left.x, y, I_{t}\right) \\
= & \operatorname{Pr}\left[\tilde{S}_{I_{t}}=1 \mid I_{t}\right] \times E_{\tilde{I}_{t+1}}\left\{v \operatorname{Pr}\left[\tilde{R}_{I_{t+1}} \geq x \mid \tilde{I}_{t+1}\right]+v(x-1) \operatorname{Pr}\left[\tilde{R}_{I_{t+1}} \geq x \mid \tilde{I}_{t+1}\right] \mid I_{t}, \tilde{S}_{I_{t}}=1\right\} \\
& +\operatorname{Pr}\left[\tilde{S}_{I_{t}}=0 \mid I_{t}\right] v x \operatorname{Pr}\left[\tilde{R}_{I_{t+1}} \geq x+1 \mid I_{t}, \tilde{S}_{I_{t}}=0\right] \\
= & \operatorname{Pr}\left[\tilde{S}_{I_{t}}=1 \mid I_{t}\right] \operatorname{vx} \operatorname{Pr}\left[\tilde{R}_{I_{t+1}}+\tilde{S}_{I_{t}} \geq x+1 \mid I_{t}, \tilde{S}_{I_{t}}=1\right] \\
& +\operatorname{Pr}\left[\tilde{S}_{I_{t}}=0 \mid I_{t}\right] v x \operatorname{Pr}\left[\tilde{R}_{I_{t+1}}+\tilde{S}_{I_{t}} \geq x+1 \mid I_{t}, \tilde{S}_{I_{t}}=0\right] \\
= & \operatorname{vx} \operatorname{Pr}\left[\tilde{R}_{t} \geq x+1 \mid I_{t}\right]
\end{aligned}
$$


and

$$
\begin{aligned}
& W\left(y, x, I_{t}\right) \\
& =\operatorname{Pr}\left[\tilde{S}_{I_{t}}=1 \mid I_{t}\right] v E\left[\min \left\{y,\left(\tilde{R}_{I_{t+1}}-(x-1)\right)^{+}\right\} \mid I_{t}, \tilde{S}_{I_{t}}=1\right] \\
& \quad+\operatorname{Pr}\left[\tilde{S}_{I_{t}}=0 \mid I_{t}\right] v E\left[\min \left\{y,\left(\tilde{R}_{I_{t+1}}-x\right)^{+}\right\} \mid I_{t}, \tilde{S}_{I_{t}}=0\right] \\
& =v E\left[\min \left\{y,\left(\tilde{R}_{I_{t}}-x\right)^{+}\right\} \mid I_{t}\right] .
\end{aligned}
$$

Finally, if $x=y$, both sellers have the same reservation price, and hence the value function can be calculated for the seller that does not sell, as in the last case above:

$$
\begin{aligned}
& W(x, x, k) \\
& \quad=v E\left[\min \left\{x,\left(\tilde{R}_{I_{t}}-x\right)^{+}\right\} \mid I_{t}\right] .
\end{aligned}
$$

This concludes the induction.

\section{Proof of Theorem 2}

\section{$\underline{\text { Proof }}$}

When sellers have different capacities, the selling price is given by the firm with higher capacity. This is given by the case $x<y$, from the previous proof:

$$
\begin{aligned}
E_{\tilde{I}_{t+1}} & \left\{W\left(y, x-1, \tilde{I}_{t+1}\right)-W\left(y-1, x, \tilde{I}_{t+1}\right) \mid I_{t}, \tilde{S}_{I_{t}}=1\right\} \\
= & v E_{\tilde{I}_{t+1}}\left\{\operatorname{Pr}\left[\tilde{R}_{I_{t+1}} \geq x \mid \tilde{I}_{t+1}\right] \mid I_{t}, \tilde{S}_{I_{t}}=1\right\} \\
= & v \operatorname{Pr}\left[\tilde{R}_{I_{t+1}} \geq x \mid I_{t}, \tilde{S}_{I_{t}}=1\right]
\end{aligned}
$$

When both firms have the same capacity, the case corresponds to $x=y$,

$$
\begin{aligned}
& E_{\tilde{I}_{t+1}}\left[W\left(x, x-1, \tilde{I}_{t+1}\right)-W\left(x-1, x, \tilde{I}_{t+1}\right) \mid I_{t}, \tilde{S}_{I_{t}}=1\right] \\
& =E_{\tilde{I}_{t+1}}\left\{v E\left[\min \left\{x,\left(\tilde{R}_{I_{t+1}}-x+1\right)^{+}\right\} \mid \tilde{I}_{t+1}\right] \mid I_{t}, \tilde{S}_{I_{t}}=1\right\} \\
& -E_{\tilde{I}_{t+1}}\left\{v(x-1) \operatorname{Pr}\left[\tilde{R}_{I_{t+1}} \geq x \mid \tilde{I}_{t+1}\right\} \mid I_{t}, \tilde{S}_{I_{t}}=1\right\} \\
& =v E_{\tilde{I}_{t+1}}\left\{E\left[\min \left\{x,\left(\tilde{R}_{I_{t+1}}-x+1\right)^{+}\right\}-(x-1) 1_{\tilde{R}_{I_{t+1}} \geq x} \mid \tilde{I}_{t+1}\right] \mid I_{t}, \tilde{S}_{I_{t}}=1\right\} \\
& =v E\left[\left\{\min \left\{x, \tilde{R}_{I_{t+1}}-x+1\right\}-(x-1)\right\} 1_{\tilde{R}_{I_{t+1}} \geq x} \mid I_{t}, \tilde{S}_{I_{t}}=1\right] \\
& =v E\left[\left\{1-\left(2 x-1-\tilde{R}_{I_{t+1}}\right)^{+}\right\} 1_{\tilde{R}_{I_{t+1}} \geq x} \mid I_{t}, \tilde{S}_{I_{t}}=1\right] \text {. }
\end{aligned}
$$




\section{Proof of Theorem 3}

\section{Proof}

Under the more general setting, the dynamic programming equation of Equation (1) is replaced by

$$
\begin{aligned}
& V_{A}^{*}\left(\mathbf{p}_{B}, x_{A}, x_{B}, I_{t}\right) \\
& =\max _{p_{A}} \operatorname{Pr}\left(\tilde{S}_{I_{t}}=1 \mid I_{t}\right)\left(\begin{array}{c}
P_{A}\left(p_{A}, p_{B}\right)\left(p_{A}-c_{A}+E_{\tilde{I}_{t+1}}\left[V_{A}^{\diamond}\left(x_{A}-1, x_{B}, \tilde{I}_{t+1}\right) \mid I_{t}, \tilde{S}_{I_{t}}=1\right]\right) \\
+P_{B}\left(p_{A}, p_{B}\right) E_{\tilde{I}_{t+1}}\left[V_{A}^{\diamond}\left(x_{A}, x_{B}-1, \tilde{I}_{t+1}\right) \mid I_{t}, \tilde{S}_{I_{t}}=1\right] \\
+\left(1-P_{A}\left(p_{A}, p_{B}\right)-P_{B}\left(p_{A}, p_{B}\right)\right) E_{\tilde{I}_{t+1}}\left[V_{A}^{\diamond}\left(x_{A}, x_{B}, \tilde{I}_{t+1}\right) \mid I_{t}, \tilde{S}_{I_{t}}=1\right]
\end{array}\right) \\
& +\operatorname{Pr}\left(\tilde{S}_{I_{t}}=0 \mid I_{t}\right) E_{\tilde{I}_{t+1}}\left[V_{A}^{\diamond}\left(x_{A}, x_{B}, \tilde{I}_{t+1}\right) \mid I_{t}, \tilde{S}_{I_{t}}=0\right]
\end{aligned}
$$

and similarly for $B$.

Given $p_{B}$, letting $\epsilon>0$ and small, the best price set by $A$ is

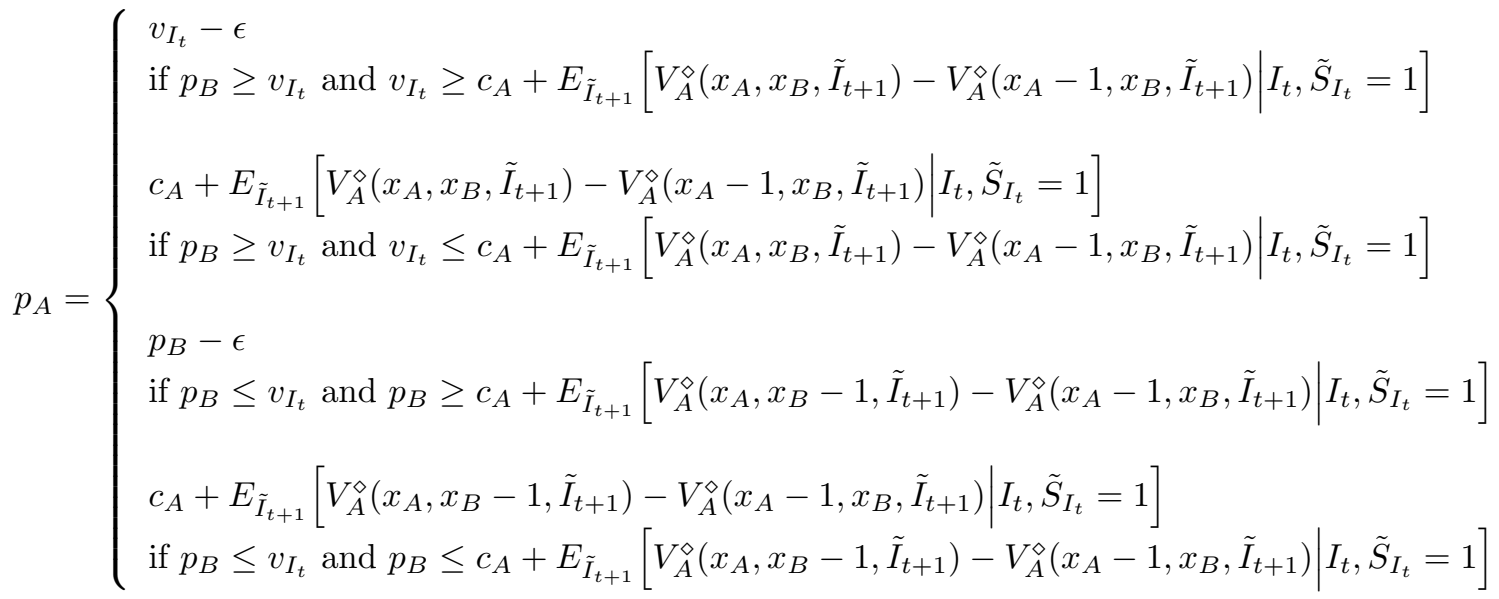

Clearly, since the best possible future per-unit profit that $\mathrm{A}$ can obtain is at most $v_{I_{t}}-c_{A}, A$ will always try to sell a unit at $t$ if $p_{B} \geq v_{I_{t}}$, since $v_{I_{t}}-c_{A} \geq E_{\tilde{I}_{t+1}}\left[V_{A}^{\diamond}\left(x_{A}, x_{B}, \tilde{I}_{t+1}\right)-V_{A}^{\diamond}\left(x_{A}-\right.\right.$ $\left.\left.1, x_{B}, \tilde{I}_{t+1}\right) \mid I_{t}, \tilde{S}_{I_{t}}=1\right]$. Hence, the second case never occurs. For the same reason, $v_{I_{t}}-c_{A} \geq$ $E_{\tilde{I}_{t+1}}\left[V_{A}^{\diamond}\left(x_{A}, x_{B}-1, \tilde{I}_{t+1}\right)-V_{A}^{\diamond}\left(x_{A}-1, x_{B}, \tilde{I}_{t+1}\right) \mid I_{t}, \tilde{S}_{I_{t}}=1\right]$ and the fourth case never occurs either when $p_{B}$ is slightly below $v_{I_{t}}$. As a result, the best-response is continuous in $p_{B}$ and the sellers engage in asymmetric Bertrand price competition with reservation prices $\min \left\{v_{I_{t}}, \triangle V_{A}^{\diamond}\left(x_{A}, x_{B}, I_{t}\right)\right\}$ for $A$ and $\min \left\{v_{I_{t}}, \triangle V_{B}^{\diamond}\left(x_{A}, x_{B}, I_{t}\right)\right\}$ for $B$, where

$$
\triangle V_{A}^{\diamond}\left(x_{A}, x_{B}, I_{t}\right)=E_{\tilde{I}_{t+1}}\left[c_{A}+V_{A}^{\diamond}\left(x_{A}, x_{B}-1, \tilde{I}_{t+1}\right)-V_{A}^{\diamond}\left(x_{A}-1, x_{B}, \tilde{I}_{t+1}\right) \mid I_{t}, \tilde{S}_{I_{t}}=1\right],
$$

and

$$
\triangle V_{B}^{\diamond}\left(x_{A}, x_{B}, I_{t}\right)=E_{\tilde{I}_{t+1}}\left[c_{B}+V_{B}^{\diamond}\left(x_{A}-1, x_{B}, \tilde{I}_{t+1}\right)-V_{B}^{\diamond}\left(x_{A}, x_{B}-1, \tilde{I}_{t+1}\right) \mid I_{t}, \tilde{S}_{I_{t}}=1\right] .
$$

This extends Lemma 1 to this setting. As a result, the value function recursion of any equilibrium is given by the joint recursion $V_{A}^{\diamond}\left(\cdot, \cdot, I_{T+1}\right)=V_{B}^{\diamond}\left(\cdot, \cdot, I_{T+1}\right)=0$, and for all $I_{t}$, for all $x_{A}, x_{B}$, 


$$
\begin{aligned}
& V_{A}^{\diamond}\left(x_{A}, x_{B}, I_{t}\right) \\
& = \begin{cases}0 & \text { if } x_{A}=0 \\
\operatorname{Pr}\left(\tilde{S}_{I_{t}}=1 \mid I_{t}\right)\left(v_{I_{t}}-c_{A}+E_{\tilde{I}_{t+1}}\left[V_{A}^{\diamond}\left(x_{A}-1,0, \tilde{I}_{t+1}\right) \mid I_{t}, \tilde{S}_{I_{t}}=1\right]\right) & \\
+\operatorname{Pr}\left(\tilde{S}_{I_{t}}=0 \mid I_{t}\right) E_{\tilde{I}_{t+1}}\left[V_{A}^{\diamond}\left(x_{A}, 0, \tilde{I}_{t+1}\right) \mid I_{t}, \tilde{S}_{I_{t}}=0\right] & \text { if } x_{A}>0, x_{B}=0 \\
\operatorname{Pr}\left(\tilde{S}_{I_{t}}=1 \mid I_{t}\right)\left(\begin{array}{c}
E_{\tilde{I}_{t+1}}\left[V_{A}^{\diamond}\left(x_{A}-1, x_{B}, \tilde{I}_{t+1}\right) \mid I_{t}, \tilde{S}_{I_{t}}=1\right] \\
+\max \left(\triangle V_{A}^{\diamond}\left(x_{A}, x_{B}, I_{t}\right), \triangle V_{B}^{\diamond}\left(x_{A}, x_{B}, I_{t}\right)\right)-c_{A}
\end{array}\right) & \\
+\operatorname{Pr}\left(\tilde{S}_{I_{t}}=0 \mid I_{t}\right) E_{\tilde{I}_{t+1}}\left[V_{A}^{\diamond}\left(x_{A}, x_{B}, \tilde{I}_{t+1}\right) \mid I_{t}, \tilde{S}_{I_{t}}=0\right] & \text { otherwise }\end{cases}
\end{aligned}
$$

and

$$
\begin{aligned}
& V_{B}^{\diamond}\left(x_{A}, x_{B}, I_{t}\right) \\
& = \begin{cases}0 & \text { if } x_{B}=0 \\
\operatorname{Pr}\left(\tilde{S}_{I_{t}}=1 \mid I_{t}\right)\left(v_{I_{t}}-c_{B}+E_{\tilde{I}_{t+1}}\left[V_{A}^{\diamond}\left(0, x_{B}-1, \tilde{I}_{t+1}\right) \mid I_{t}, \tilde{S}_{I_{t}}=1\right]\right) & \\
+\operatorname{Pr}\left(\tilde{S}_{I_{t}}=0 \mid I_{t}\right) E_{\tilde{I}_{t+1}}\left[V_{A}^{\diamond}\left(0, x_{B}, \tilde{I}_{t+1}\right) \mid I_{t}, \tilde{S}_{I_{t}}=0\right] & \text { if } x_{B}>0, x_{A}=0 \\
\operatorname{Pr}\left(\tilde{S}_{I_{t}}=1 \mid I_{t}\right)\left(\begin{array}{c}
E_{\tilde{I}_{t+1}}\left[V_{B}^{\diamond}\left(x_{A}, x_{B}-1, \tilde{I}_{t+1}\right) \mid I_{t}, \tilde{S}_{I_{t}}=1\right] \\
+\max \left(\triangle V_{A}^{\diamond}\left(x_{A}, x_{B}, I_{t}\right), \triangle V_{B}^{\diamond}\left(x_{A}, x_{B}, I_{t}\right)\right)-c_{B}
\end{array}\right) & \\
+\operatorname{Pr}\left(\tilde{S}_{I_{t}}=0 \mid I_{t}\right) E_{\tilde{I}_{t+1}}\left[V_{A}^{\diamond}\left(x_{A}, x_{B}, \tilde{I}_{t+1}\right) \mid I_{t}, \tilde{S}_{I_{t}}=0\right] & \text { otherwise }\end{cases}
\end{aligned}
$$

Existence and uniqueness of equilibrium follow.

\section{Proof of Theorem 4}

\section{Proof}

From Theorem 2, we know that the subgame for period $t=1$ exists and is unique. This leads to value functions

$$
E_{I_{0}} V_{A}^{\diamond}\left(x_{A}, x_{B}, I_{1}\right)= \begin{cases}\theta & \text { if } x_{A} \geq 1, x_{B}=0 \\ 0 & \text { otherwise }\end{cases}
$$

where $\theta=\operatorname{Pr}\left(S_{I_{1}}=1 \mid I_{0}\right)$, and similarly for B. Consider the game in period $t=0$ with $x_{A}=x_{B}=1$ with $v<\theta$. If $p_{B}>v$, then $\mathrm{A}$ will set $p_{A}=v$ because it does not sell at $t=0$, then it will make zero profit. If $p_{B} \leq v$, then $\mathrm{B}$ will set $p_{A}>p_{B}$ and let $\mathrm{B}$ sell. As a result, there are two equilibria: $p_{A}=v$ and $p_{B}>v$, and $p_{B}=v$ and $p_{A}>v$. 


\section{Proof of Theorem 5}

\section{Proof}

In order to prove the theorem, we show by backwards induction that for all $t=T, \ldots, 1$, for all $I_{t+1}$, a unique subgame-perfect equilibrium exists starting from state $I_{t+1}$. The equilibrium results in value functions as follows. Let $x=\max _{j}\left\{x_{j}\right\}$. If $x_{i}<x_{\text {max }}$ then

$$
V_{i}\left(\mathbf{x}, I_{t+1}\right)=v x_{i} \operatorname{Pr}\left[\tilde{R}_{I_{t+1}} \geq 1+\sum_{j} x_{j}-x_{\max } \mid I_{t+1}\right]
$$

if $x_{i}=x_{\max }$,

$$
V_{i}\left(\mathbf{x}, I_{t+1}\right)=v E\left[\min \left\{x_{\max },\left(\tilde{R}_{I_{t+1}}-\sum_{j} x_{j}+x_{\max }\right)^{+}\right\} \mid I_{t+1}\right] .
$$

It is clear that the property is true for $t=T$, because $\tilde{R}_{I_{t+1}}=0$ and $V_{i}\left(\mathbf{x}, I_{T+1}\right)=0$.

Assume that the property is true for all states $I_{t+1}$, and consider the pricing game starting from a state $I_{t}$. Without loss of generality, assume that $x_{1} \leq \ldots \leq x_{m-1}<x_{\max }$ and $x_{m}=\ldots=x_{n}=$ $x_{\text {max }}$. For this purpose, we let $I_{t+1}=\left(I_{t}, \tilde{S}_{I_{t}}=1\right)$ and calculate the reservation values of each firm. We have two cases to consider: when $m=n$ (only one firm has maximum capacity) and $m<n$ (at least two have maximum capacity).

First, if $m=n$,

- if $i, k<m$, then

$$
\begin{aligned}
V_{i}(\mathbf{x} & \left.-\mathbf{e}_{k}, I_{t+1}\right)-V_{i}\left(\mathbf{x}-\mathbf{e}_{i}, I_{t+1}\right) \\
& =v x_{i} \operatorname{Pr}\left[\tilde{R}_{I_{t+1}} \geq \sum_{j \neq m} x_{j} \mid I_{t+1}\right]-v\left(x_{i}-1\right) \operatorname{Pr}\left[\tilde{R}_{I_{t+1}} \geq \sum_{j \neq m} x_{j} \mid I_{t+1}\right] \\
& =v \operatorname{Pr}\left[\tilde{R}_{I_{t+1}} \geq \sum_{j} x_{j}-x_{\max } \mid I_{t+1}\right]
\end{aligned}
$$

- if $i<m$ and $k=m$ and $x_{i}=x_{k}-1=x_{\max }-1$, then

$$
\begin{aligned}
V_{i}(\mathbf{x} & \left.-\mathbf{e}_{k}, I_{t+1}\right)-V_{i}\left(\mathbf{x}-\mathbf{e}_{i}, I_{t+1}\right) \\
& =v E\left[\min \left\{x_{i},\left(\tilde{R}_{I_{t+1}}-\sum_{j \neq m} x_{j}\right)^{+}\right\} \mid I_{t+1}\right]-v\left(x_{i}-1\right) \operatorname{Pr}\left[\tilde{R}_{I_{t+1}} \geq \sum_{j \neq m} x_{j} \mid I_{t+1}\right] \\
& <v \operatorname{Pr}\left[\tilde{R}_{I_{t+1}} \geq \sum_{j} x_{j}-x_{\max } \mid I_{t+1}\right]
\end{aligned}
$$


- if $i<m$ and $k=m$ and $x_{i}<x_{k}-1=x_{\max }-1$, then

$$
\begin{aligned}
V_{i}(\mathbf{x} & \left.-\mathbf{e}_{k}, I_{t+1}\right)-V_{i}\left(\mathbf{x}-\mathbf{e}_{i}, I_{t+1}\right) \\
& =v x_{i} \operatorname{Pr}\left[\tilde{R}_{I_{t+1}} \geq \sum_{j \neq m} x_{j}+1 \mid I_{t+1}\right]-v\left(x_{i}-1\right) \operatorname{Pr}\left[\tilde{R}_{I_{t+1}} \geq \sum_{j \neq} x_{j} \mid I_{t+1}\right] \\
& <v \operatorname{Pr}\left[\tilde{R}_{I_{t+1}} \geq \sum_{j} x_{j}-x_{\max } \mid I_{t+1}\right]
\end{aligned}
$$

- if $i=m$ and $k<m$, then

$$
\begin{aligned}
V_{i}\left(\mathbf{x}-\mathbf{e}_{k}, I_{t+1}\right)-V_{i}\left(\mathbf{x}-\mathbf{e}_{i}, I_{t+1}\right) & =v E\left[\min \left\{x_{i},\left(\tilde{R}_{I_{t+1}}-\sum_{j \neq m} x_{j}+1\right)\right\} I_{t+1}\right] \\
= & v E\left[\min \left\{x_{i}-1,\left(\tilde{R}_{I_{t+1}}-\sum_{j \neq m} x_{j}\right)^{+}\right\} \mid I_{t+1}\right] \\
= & v \operatorname{Pr}\left[\tilde{R}_{I_{t+1}} \geq \sum_{j} x_{j}-x_{\max } \mid I_{t+1}\right]
\end{aligned}
$$

In this scenario, the equilibrium is that all firms set a price equal to $v \operatorname{Pr}\left[\tilde{R}_{I_{t+1}} \geq \sum_{j} x_{j}-x_{\max } \mid I_{t+1}\right]$, and the customer (if it arrives) is served by a firm $k<m$. Indeed, this is the reservation value of all firms if $k<m$. On the other hand, if the winner is $k=m$, then the rest of the firms would be willing to undercut its price. In addition, all other prices are either above or below the reservation value and hence cannot be an equilibrium.

On the other hand, if $k<m$ (at least two firms have maximum capacity),

- if $i, k<m$, then

$$
\begin{aligned}
V_{i}(\mathbf{x} & \left.-\mathbf{e}_{k}, I_{t+1}\right)-V_{i}\left(\mathbf{x}-\mathbf{e}_{i}, I_{t+1}\right) \\
& =v \operatorname{Pr}\left[\tilde{R}_{I_{t+1}} \geq \sum_{j} x_{j}-x_{\max } \mid I_{t+1}\right]
\end{aligned}
$$

- if $i<m$ and $k \geq m$, then

$$
\begin{aligned}
V_{i}(\mathbf{x} & \left.-\mathbf{e}_{k}, I_{t+1}\right)-V_{i}\left(\mathbf{x}-\mathbf{e}_{i}, I_{t+1}\right) \\
& =v x_{i} \operatorname{Pr}\left[\tilde{R}_{I_{t+1}} \geq \sum_{j} x_{j}-x_{\max } \mid I_{t+1}\right]-v\left(x_{i}-1\right) \operatorname{Pr}\left[\tilde{R}_{I_{t+1}} \geq \sum_{j} x_{j}-x_{\max } \mid I_{t+1}\right] \\
& =v \operatorname{Pr}\left[\tilde{R}_{I_{t+1}} \geq \sum_{j} x_{j}-x_{\max } \mid I_{t+1}\right]
\end{aligned}
$$


- if $i \geq m$, then

$$
\begin{aligned}
V_{i}(\mathbf{x} & \left.-\mathbf{e}_{k}, I_{t+1}\right)-V_{i}\left(\mathbf{x}-\mathbf{e}_{i}, I_{t+1}\right) \\
= & v E\left[\min \left\{x_{i},\left(\tilde{R}_{I_{t+1}}-\sum_{j} x_{j}+x_{\max }+1\right)\right\} \mid I_{t+1}\right] \\
& \quad-v\left(x_{i}-1\right) \operatorname{Pr}\left[\tilde{R}_{I_{t+1}} \geq \sum_{j} x_{j}-x_{\max } \mid I_{t+1}\right] \\
& <v \operatorname{Pr}\left[\tilde{R}_{I_{t+1}} \geq \sum_{j} x_{j}-x_{\max } \mid I_{t+1}\right]
\end{aligned}
$$

Hence, in this scenario, the only equilibrium is that one firm such that $k \geq m$ sets a price equal to $v E\left[\min \left\{x_{i},\left(\tilde{R}_{I_{t+1}}-\sum_{j \neq m} x_{j}+1\right)^{+}\right\} \mid I_{t+1}\right]-v\left(x_{i}-1\right) \operatorname{Pr}\left[\tilde{R}_{I_{t+1}} \geq \sum_{j} x_{j}-x_{\max } \mid I_{t+1}\right]=$ $v E\left[\min \left\{1, \tilde{R}_{I_{t+1}}-\sum_{j} x_{j}+2\right\} 1_{\tilde{R}_{I_{t+1}} \geq \sum_{j} x_{j}-x_{\max }} \mid I_{t+1}\right]$ and sells to the customer.

As a result, in both cases, the price strategy equilibrium is unique (although the winners are selected randomly). The resulting value functions are thus uniquely defined. If $x_{i}=x_{\max }$ and firm $k$ sells to the customer,

$$
\begin{aligned}
V_{i}\left(\mathbf{x}, I_{t}\right)= & \operatorname{Pr}\left[\tilde{S}_{I_{t}}=1 \mid I_{t}\right] E_{\tilde{I}_{t+1}}\left[V_{i}\left(\mathbf{x}-\mathbf{e}_{k}, \tilde{I}_{t+1}\right) \mid I_{t}, \tilde{S}_{I_{t}}=1\right] \\
& +\operatorname{Pr}\left[\tilde{S}_{I_{t}}=0 \mid I_{t}\right] E_{\tilde{I}_{t+1}}\left[V_{i}\left(\mathbf{x}, \tilde{I}_{t+1}\right) \mid I_{t}, \tilde{S}_{I_{t}}=0\right] \\
= & \operatorname{Pr}\left[\tilde{S}_{I_{t}}=1 \mid I_{t}\right] E_{\tilde{I}_{t+1}}\left[v \min \left\{x_{i},\left(\tilde{R}_{I_{t+1}}-\sum_{j \neq i} x_{j}+1\right)\right\} \mid I_{t}, \tilde{S}_{I_{t}}=1\right] \\
& +\operatorname{Pr}\left[\tilde{S}_{I_{t}}=0 \mid I_{t}\right] E_{\tilde{I}_{t+1}}\left[v \min \left\{x_{i},\left(\tilde{R}_{I_{t+1}}-\sum_{j \neq i} x_{j}\right)^{+}\right\} \mid I_{t}, \tilde{S}_{I_{t}}=0\right] \\
= & E\left[v \min \left\{x_{\max },\left(\tilde{R}_{t}-\sum_{j} x_{j}+x_{\max }\right)^{+}\right\} \mid I_{t}\right] .
\end{aligned}
$$

If $x_{i}<x_{\max }$ (this is calculated assuming that there is only one firm with capacity $x_{\max }$; the identical 
result is derived when more than one has capacity $x_{\max }$ )

$$
\begin{aligned}
V_{i}\left(\mathbf{x}, I_{t}\right)= & \operatorname{Pr}\left[\tilde{S}_{I_{t}}=1 \mid I_{t}\right] E_{\tilde{I}_{t+1}}\left[\operatorname{Pr}\left[\tilde{R}_{I_{t+1}} \geq \sum_{j} x_{j}-x_{\max }\right]+V_{i}\left(\mathbf{x}-\mathbf{e}_{i}, \tilde{I}_{t+1}\right) \mid I_{t}, \tilde{S}_{I_{t}}=1\right] \\
& +\operatorname{Pr}\left[\tilde{S}_{I_{t}}=0 \mid I_{t}\right] E_{\tilde{I}_{t+1}}\left[V_{i}\left(\mathbf{x}, \tilde{I}_{t+1}\right) \mid I_{t}, \tilde{S}_{I_{t}}=0\right] \\
= & \operatorname{Pr}\left[\tilde{S}_{I_{t}}=1 \mid I_{t}\right] E_{\tilde{I}_{t+1}}\left[v x_{i} \operatorname{Pr}\left[\tilde{R}_{I_{t+1}} \geq \sum_{j} x_{j}-x_{\max }\right] \mid I_{t}, \tilde{S}_{I_{t}}=1\right] \\
& +\operatorname{Pr}\left[\tilde{S}_{I_{t}}=0 \mid I_{t}\right] E_{\tilde{I}_{t+1}}\left[v x_{i} \operatorname{Pr}\left[\tilde{R}_{I_{t+1}} \geq \sum_{j} x_{j}-x_{m a x}+1\right] \mid I_{t}, \tilde{S}_{I_{t}}=0\right] \\
= & \operatorname{vx} \operatorname{Pr}\left[\tilde{R}_{t} \geq \sum_{j} x_{j}-x_{\max }+1 \mid I_{t}\right] .
\end{aligned}
$$

This completes the induction.

Q.E.D

\section{Proof of Theorem 6}

$\underline{\text { Proof }}$

$\overline{\text { Let }}_{\text {max }}=\max _{j} x_{j}$ and $M=\left\{i \mid x_{i}=x_{\max }\right\}$. Thus, from the previous proof,

$$
\begin{aligned}
\frac{V_{\text {industry }}\left(\mathbf{x}, I_{t}\right)}{v}= & \left(n-|M| x_{\max }\right) \operatorname{Pr}\left[\tilde{R}_{t} \geq n-x_{\max }+1 \mid I_{t}\right] \\
& +|M| E\left[\min \left\{x_{\max },\left(\tilde{R}_{t}-n+x_{\max }\right)^{+}\right\} \mid I_{t}\right] \\
= & n \operatorname{Pr}\left[\tilde{R}_{t} \geq n-x_{\max }+1 \mid I_{t}\right] \\
& +|M| E\left[\min \left\{x_{\max },\left(\tilde{R}_{t}-n+x_{\max }\right)^{+}\right\}-x_{\max } 1_{\tilde{R}_{t} \geq n-x_{\max }+1} \mid I_{t}\right] \\
= & E\left[\left(n+|M| \min \left\{0, \tilde{R}_{t}-n\right\}\right) 1_{\tilde{R}_{t} \geq n-x_{\max }+1} \mid I_{t}\right]
\end{aligned}
$$

This expression is decreasing in $|M|$. It is also increasing in $x_{\text {max }}$ because, when $\tilde{R}_{t} \geq n-x_{\text {max }}+1$, $n+|M| \min \left\{0, \tilde{R}_{t}-n\right\} \geq n-|M|\left(x_{\max }-1\right) \geq 0$ (recall that $\left.|M| x_{\max } \leq n\right)$. The bounds are derived by setting $|M|=1$ and $x_{\max }=n$, and $|M|=n$ and $x_{\max }=1$.

Q.E.D 